Inmigrantes en el mercado laboral: análisis de la diferencia salarial para Argentina 2004-2015

Sofía Laurito

Octubre 2018

Universidad Nacional de La Plata

Maestría en Economía

Directora: María Florencia Pinto 


\title{
Inmigrantes en el mercado laboral: análisis de la diferencia salarial para Argentina 2004-2015 ${ }^{1}$ \\ Sofía Laurito
}

\begin{abstract}
Resumen
Este trabajo investiga la diferencia salarial existente entre nativos e inmigrantes en Argentina para el período 2004-2015. Utilizando la Encuesta Permanente de Hogares se realiza una descomposición de la brecha salarial, tanto para la media de la distribución del ingreso, como para el resto de la distribución. Los resultados sugieren que los inmigrantes cobran en promedio $15.4 \%$ menos que los nacidos en Argentina y la brecha aumenta cuando nos movemos hacia cuantiles más altos de la distribución del ingreso. Como máximo es posible explicar aproximadamente el $70 \%$ de la diferencia en los extremos de la distribución a partir de características observables como la educación, selección en empleos informales con calificaciones ocupacionales de menor paga y en diferentes sectores de actividad económica. Finalmente, se evalúa la posible existencia de asimilación no contemplada en las descomposiciones anteriores y no se logra encontrar evidencia a favor de dicha teoría.
\end{abstract}

\footnotetext{
${ }^{1}$ Este trabajo constituye mi tesis de Maestría en Economía de la Universidad Nacional de La Plata, dirigida por María Florencia Pinto, a quien agradezco enormemente por su valiosa guía y apoyo. Mis agradecimientos también a Federico Borrone por los productivos intercambios realizados a lo largo de todo el proceso y su incentivo constante. Cualquier error del presente trabajo es de mi entera responsabilidad. Email: sofia.laurito@gmail.com
} 


\section{Índice}

1. Introducción 3

2. Metodología $\quad 9$

2.1. Análisis de segmentación . . . . . . . . . . . . . . . . . . . . . 9

2.2. Descomposición de diferencia salarial . . . . . . . . . . . . . . . . . . 10

3. Descripción de la muestra

4. Resultados 20

4.1. Segmentación . . . . . . . . . . . . . . . . 20

4.2. Diferencia salarial y descomposiciones . . . . . . . . . . . . . . . 22

4.3. Evidencia de (no) asimilación . . . . . . . . . . . . . . . . . . . 29

5. Conclusiones 36 


\section{Introducción}

Las migraciones internacionales constituyen un fenómeno de creciente importancia a nivel mundial; los movimientos de personas generan significativos efectos económicos, sociales, demográficos y culturales, tanto en el país de origen como en los países receptores. Las fuertes disparidades en los niveles de desarrollo económico, las desiguales oportunidades de empleo, la inestabilidad política y la violencia social constituyen los factores más importantes de la expulsión y atracción de las migraciones a escala mundial (Maurizio, 2008).

En Argentina, la composición de las migraciones ha ido cambiando con el correr de su historia, hasta mediados del siglo XX era receptor de inmigrantes procedentes de Europa y en la actualidad, constituye principalmente un destino atractivo para los latinoamericanos que buscan dejar sus países. Con una ley de migraciones que promueve la protección y el respeto de los derechos de los inmigrantes ${ }^{2}$, es muy probable que los migrantes latinoamericanos continúen llegando en el mediano y largo plazo, insertándose en el mercado de trabajo local e integrándose a la sociedad argentina.

Según cifras del Banco Mundial, en 2015 Argentina se encontró entre los primeros 30 países del mundo con mayor stock de inmigrantes internacionales, y el mayor en América del Sur, más que triplica su promedio (Figura 1). Su importancia no solo radica en términos absolutos sino también como porcentaje del total de la población (Figura 2).

\footnotetext{
${ }^{2}$ Ley de Migraciones 25,871 promulgada en enero de 2004.
} 
Figura 1: Stock de inmigrantes

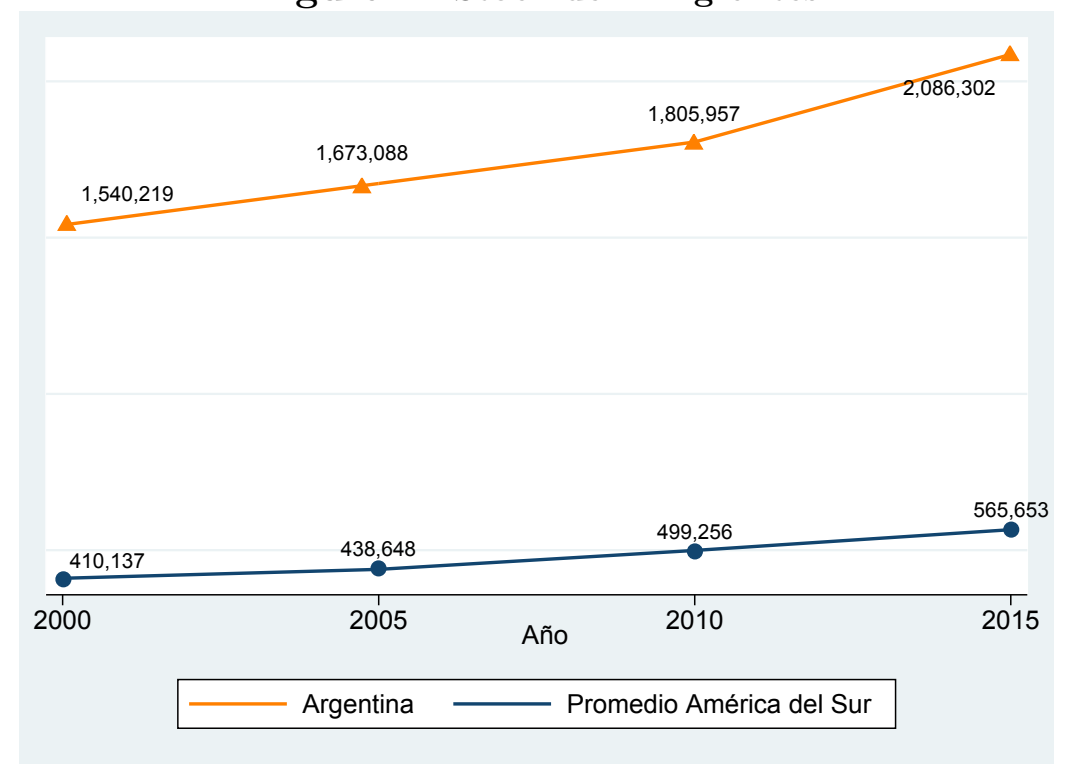

Fuente:World Development Indicators, Word Bank. El promedio de América del sur incluye los siguientes países: Argentina, Venezuela, Brasil, Chile, Ecuador, Paraguay, Bolivia, Colombia, Perú y Uruguay.

Figura 2: Stock de inmigrantes (porcentaje de la población total)

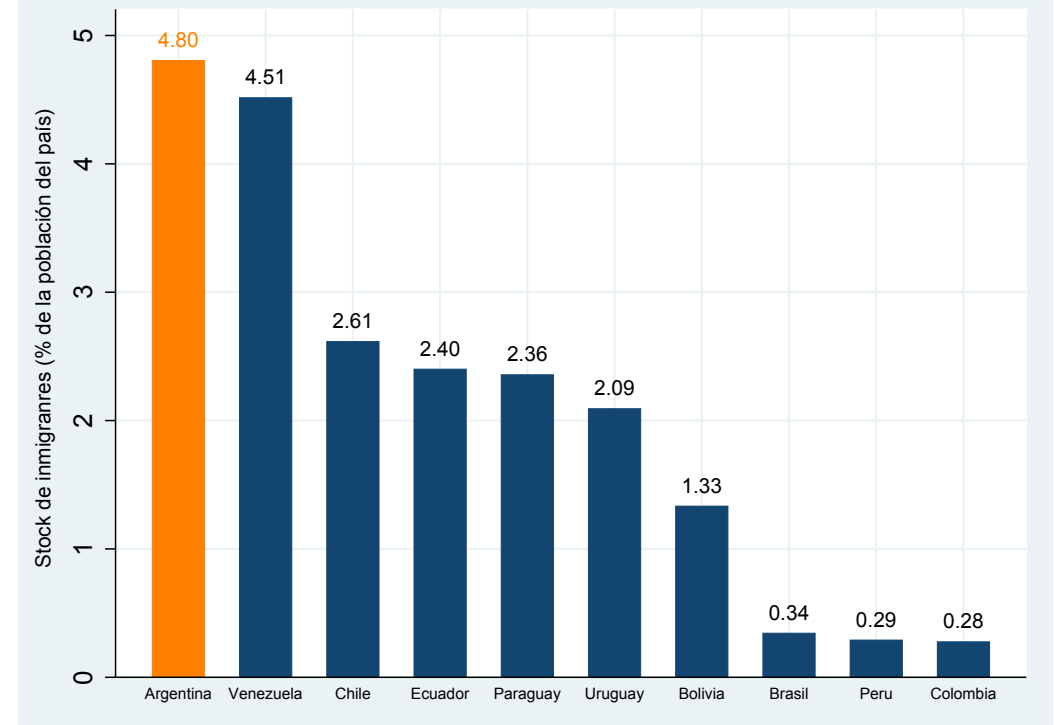

Fuente:World Development Indicators, Word Bank. 
La existencia de leyes específicas no es suficiente para garantizar la igualdad de derechos entre nativos e inmigrantes, esto se ve reflejado en la persistencia de situaciones de vulnerabilidad que afectan a los trabajadores migrantes y a sus familias. La irregularidad laboral es una de ellas, que se manifiesta en una alta precariedad y desigualdad salarial, lo que conlleva a la exclusión y a la marginalidad social.

La evidencia internacional ha comprobado que en la mayoría de los países, los inmigrantes suelen tener menores salarios que los nativos y, en general, se ha abordado la temática a través de dos corrientes: la literatura de la "discriminación" basada en la descomposición de Oaxaca Ronald (1973) y la teoría de asimilación introducida por Chiswick (1978).

La primera corriente trata de explicar la brecha salarial diferenciando la misma en dos componentes, uno referido a las diferencias en características observables de los individuos que se espera que generen diferencias salariales (como por ejemplo la educación, la edad, la experiencia, el tipo de empleo, etc.) y el otro referido a las características inobservables (hablidades personales, preferencias, etc.) que suele asociarse también con discriminación.

Dentro de esta línea de investigación se encuentran trabajos como el de Elliott y Lindley (2008), quienes analizan los determinantes de la penalidad salarial observada en el Reino Unido para inmigrantes y nativos no blancos. Sus resultados sugieren que, incluso después de tener en cuenta el hecho de que estos grupos de individuos se segregan en determinadas ocupaciones, sigue existiendo una importante diferencia salarial que no puede ser explicada por características observables. Canal-Domínguez y Rodríguez-Gutiérrez (2008) analizan la brecha salarial entre nativos e inmigrantes en España con datos para el año 2002 y encuentran que el grupo de inmigrantes posee un salario promedio más bajo que los trabajadores nativos, teniendo características observables más desfavorables. Además, encuentran que la diferencia salarial y el componente no explicado de esta diferencia es mayor en la parte más baja de la distribución de salarios. Hunt (2012) investiga la brecha 
salarial para trabajadores varones extranjeros en Gran Bretaña durante el período 1993-2009 en toda la distribución del ingreso; sorprendentemente, encuentra que en promedio los inmigrantes ganan más que los nativos, situación que se mantiene en cuantiles más altos de la distribución del ingreso pero que se revierte en cuantiles más bajos. La autora atribuye sus resultados a que los inmigrantes poseen mayor nivel en características que benefician el nivel salarial, igualmente argumenta que dado el nivel de dichas características, los salarios deberían ser en promedio aún mayores y por lo tanto persiste una penalidad solo por pertenecer al grupo inmigrante. Ma (2016) explora los determinantes de las diferencias salariales entre los migrantes de zonas rurales a urbanas y los residentes urbanos locales en China en el período 2002-2013; sugiere que las características individuales, la localización regional y las diferencias de distribución entre la industria, el sector público y privado son los principales factores causantes de las diferencias salariales. Para Argentina, Montoya y Giordano (2012) encuentran que efectivamente los inmigrantes (tanto limítrofes como no limítrofes) tienen salarios menores que los nativos en la media de la distribución para el año 2011 en Gran Buenos Aires, y parte de dicha diferencia salarial se debe a que los inmigrantes están sobrerrepresentados en los sectores de la construcción, la economía doméstica y la venta al por menor, que a su vez son más propensos a la informalidad y la desprotección de la legislación laboral.

La segunda corriente postula que, si bien al principio puede existir una brecha salarial que desfavorece a los inmigrantes, con el tiempo el salario de los inmigrantes tiende a converger al salario de los nativos gracias al proceso de asimilación, esto es, el perfeccionamiento del lenguaje, la adquisición de calificaciones culturales (como el dialecto y códigos laborales) y de capital humano en general. En esta línea, Borjas (1985), separa a los inmigrantes en cohortes según años de llegada a Estados Unidos para construir datos de panel y reexamina una hipótesis ampliamente confirmada por otros trabajos que utilizan datos de corte transversal: los ingresos de los inmigrantes en Estados Unidos crecen a medida que se van asimilando al país, y que existe una 
ventana de 10-15 años luego de la llegada al país para que incluso sobrepasen los ingresos de los nativos. Separa a los inmigrantes en cohortes según años de llegada y analiza los salarios al interior de cada cohorte utilizando datos censales para $1970 \mathrm{y}$ 1980, encuentra que el efecto asimilación es mucho menor al encontrado por trabajos anteriores, y lo atribuye la caída en la "calidad" de inmigrantes admitidos en Estados Unidos desde 1950. Smith, (2003) analiza el proceso de asimilación de individuos latinos en Estados Unidos, en relación a su nivel educativo y sus salarios. Encuentra que cada nueva generación de latinos, ha podido disminuir la brecha en términos educativos (y consecuentemente, en términos salariales) llegando no sólo a superar el nivel educativo de sus padres, sino a alcanzar la situación económica de sus pares nativos blancos. Asimismo, Card (2005) se focaliza en responder dos interrogantes para el mercado laboral de Estados Unidos: el primero, es si los inmigrantes reducen las oportunidades laborales de los nativos con menores habilidades; el segundo es si, con el tiempo, logran integrarse a la economía doméstica. Con respecto a la primera cuestión, el autor vuelve a confirmar que aunque la inmigración afecta la oferta relativa de grupos con diferentes habilidades, los resultados laborales de nativos poco calificados no se ven afectados. Con respecto al efecto asimilación, el autor compara el desempeño educativo de los hijos de inmigrantes (nacidos en Estados Unidos) con el de los nativos y sugiere un rápido progreso de los inmigrantes de segunda generación, logrando niveles educativos mayores al promedio. Borjas (2015) vuelve a abordar el tema para Estados Unidos, analizando la tendencia de largo plazo de los salarios de inmigrantes, a partir de los censos 1970-2010. No solo observa efectos de cohorte, con cohortes más recientes recibiendo menores salarios (cohortes más recientes de inmigrantes, tienen mayor diferencia salarial con los nativos), sino que también hay diferencias en la tasa de crecimiento salarial, esto es, las cohortes más recientes presentan menor tasa de asimilación con el salario de los nativos.

Por otro lado, Nielsen, Rosholm, Smith, y Husted (2004) juntan ambas corrientes modificando la metodología de Oaxaca-Blinder y dividen la brecha en tres compo- 
nentes: características observables, características inobservables y efecto asimilación. Así, estiman ecuaciones salariales separadas para nativos y distintos grupos de inmigrantes usando datos de panel para Dinamarca, concluyendo que la brecha salarial es causada por falta de calificaciones, la poca experiencia laboral acumulada y una asimilación incompleta. Aunque no encuentran evidencia sólida de discriminación severa, mencionan la posibilidad de que la poca experiencia laboral de los inmigrantes daneses pueda deberse a fuerzas discriminatorias en el proceso de empleo, lo que dificulta obtener experiencia laboral y concluir el proceso de asimilación.

El presente trabajo tiene como objetivo contribuir al análisis del mercado laboral inmigrante en Argentina, desde la perspectiva de la diferencia salarial existente entre nativos e inmigrantes a través de tres puntos de vista. En primer lugar, se examina el rol de la segmentación en el mercado laboral entre ambos grupos, se encuentra que los inmigrantes tienen mayor probabilidad que los nativos de encontrarse en empleos con baja calificación ocupacional y sectores de actividad como la construcción, el comercio, servicio doméstico y la industria. En segundo lugar, se descompone la diferencia encontrada para los ingresos laborales tanto en la media como a lo largo de la distribución del ingreso. Los resultados sugieren que los inmigrantes cobran en promedio $15.4 \%$ menos que los nacidos en Argentina y la brecha aumenta cuando nos movemos hacia cuantiles más altos de la distribución del ingreso. Además como máximo es posible explicar el $60 \%$ de la diferencia a partir de características observables como la educación, selección en empleos informales con calificaciones ocupacionales de menor paga y en diferentes sectores de actividad económica. Por último, el trabajo evalúa la hipótesis de asimilación para entender si parte de la brecha es circunstancial y puede deberse a la falta de adquisición de características y comportamientos culturales. En este sentido, no se encuentra evidencia para verificar un proceso de asimilación en Argentina.

El resto del trabajo se estructura de la siguiente forma: en la siguiente sección se expone la metodología utilizada en el análisis de segmentación así como la empleada 
en la descomposición de brecha salarial; en la sección 3 se presenta la información utilizada y se realiza una descripción de la muestra; en la sección 4 se presentan los principales resultados; por último, se exponen las conclusiones obtenidas a lo largo de todo el trabajo.

\section{Metodología}

A continuación, se presenta la metodología a utilizar para el análisis de segmentación y de descomposición salarial, primero en la media y luego en toda la distribución del ingreso. Para la evaluación de segmentación en el mercado laboral argentino, se realiza un logit multinomial empleado por Elliott y Lindley (2008); para el análisis de descomposición en la media, se emplea la metodología propuesta por Oaxaca-Blinder (1973) y por último para la descomposición en toda la distribución del ingreso se utiliza la extensión propuesta por Melly (2006).

\subsection{Análisis de segmentación}

El análisis de segmentación intenta explicar la probabilidad de que un individuo pertenezca a cierta calificación ocupacional o sector de actividad dependiendo de su condición de inmigrante. Siguiendo a Elliott y Lindley (2008), se estima un modelo logit multinomial con una variable categórica como variable dependiente, y se incluye un indicador de condición de inmigrante como principal regresor. Las categorías de calificación ocupacional son profesional, técnico, operario y no calificado, y las de sector de actividad son agricultura y minería, industria, construcción, comercio, servicio doméstico y servicios. ${ }^{3}$ Un efecto marginal positivo indica cuánto mayor es

\footnotetext{
${ }^{3}$ En la actividad caratulada como Servicios se incluyen las siguientes actividades: Suministro de Electricidad, Gas, Vapor y Aire Acondicionado; Suministro De Agua; Alcantarillado, Gestión de Desechos y Actividades de Saneamiento; Transporte y Almacenamiento; Alojamiento y Servicios de Comidas; Información y Comunicación; Actividades Financieras y de Seguros; Actividades Inmobiliarias; Actividades Profesionales, Científicas y Técnicas; Actividades Administrativas y Servicios de Apoyo; Administración Pública y Defensa; Planes de Seguro Social Obligatorio; Enseñanza;
} 
la probabilidad condicional en $X$ en de estar empleado en determinado sector de actividad o de tener determinada calificación ocupacional para un inmigrante que para un nativo en relación a la calificación/sector omitida/o.

Sea $Z_{i}$ una variable que puede tomar distintos valores, en este caso, de calificaciones ocupacionales: $C O_{1}, \ldots, C O_{H}^{4}$ y $x_{i}$ un vector de características tanto de capital humano como socioeconómicas (se incluyen: el principal regresor que es la variable de origen y otras como sexo, edad, edad al cuadrado, educación, región geográfica, estado civil, categoría ocupacional y antigüedad). La probabilidad condicional de que un individuo pertenezca a una categoría específica $H$, puede escribirse como:

$$
P_{i h}=P\left(Z_{i}=C O_{h}\right)=\frac{\exp \left(\alpha_{h} x_{i}\right)}{1+\sum_{k=1}^{H-1}\left(\alpha_{h} x_{i}\right)}
$$

para $h=1,2, \ldots H-1 \mathrm{y}$

$$
P_{i H}=\frac{1}{1+\sum_{k=1}^{H-1} \exp \left(\alpha_{k} x_{i}\right)}
$$

Para que $\sum_{h=1}^{H}\left(P_{i h}\right)=1$, la ecuación (2) se estima para el total de la muestra de inmigrantes y nativos, donde $P_{i H}$ es la probabilidad del individuo $i$ de estar empleado con la calificación ocupacional $h$ y $\alpha_{k}$ es el vector de coeficientes correspondientes a la k-ésima ocupación.

\subsection{Descomposición de diferencia salarial}

Para analizar la diferencia salarial entre los dos grupos poblacionales se propone utilizar primero la metodología de Oaxaca R. (1973) y Blinder A. S. (1973) para descomponer la brecha de ingresos en la media de la distribución. Luego, la metodología propuesta por Melly (2006) nos permite obtener resultados sobre la misma descomposición pero a lo largo de toda la distribución del salario.

Salud Humana y Servicios Sociales; Artes, Entretenimiento y Recreación; Otras Actividades de Servicios; Actividades de Organizaciones y Organismos Extraterritoriales.

${ }^{4} \mathrm{El}$ análisis es análogo utilizando sectores de actividad en vez de calificaciones ocupacionales. 
Siguiendo a Oaxaca y Blinder (1973) se parte del siguiente modelo lineal separable en características observables e inobservables para explicar el salario de los dos grupos poblacionales de interés:

$$
y_{g}=x_{g} * \beta_{g}+v_{g}
$$

donde $g$ indica la pertenencia al grupo de origen $(g=N$ se refiere a nativos y $g=I$ a inmigrantes), $y_{g}$ es el logaritmo del salario horario, $x_{g}$ es el vector de características tanto de capital humano como socioeconómicas (se incluyen, sexo, edad, edad al cuadrado, educación, región geográfica, estado civil, categoría ocupacional, antigüedad, calificación ocupacional, informalidad y sector de actividad), $\beta_{g}$ representa el retorno salarial de la característica $x$ para el grupo $g . v_{g}$ es el término inobservable con media condicional cero: $E\left(v_{g} \mid X\right)=0$.

La brecha salarial bruta se define como $\Delta=y_{N}-y_{I}$, que puede expresarse de la siguiente manera:

$$
\Delta^{\mu}=E\left(Y \mid d_{i}=1\right)-E\left(Y \mid d_{i}=0\right)
$$

o como:

$$
\Delta^{\mu}=E\left(X \mid d_{i}=1\right) * \beta_{N}-E\left(X \mid d_{i}=0\right) * \beta_{I}
$$

Donde $d_{i}$ es una dummy de origen que indica si el individuo es nativo $\left(d_{i}=1\right)$ o inmigrante $\left(d_{i}=0\right)$.

Como $\Delta^{\mu}$ es una magnitud observable y $E\left(v_{g} \mid X\right)=0$, podemos sumar y restar el salario contrafáctico que los trabajadores inmigrantes hubiesen tenido si fuesen remunerados de acuerdo a la misma estructura salarial de los nativos $E(X \mid d=$ $0) * \beta_{N}$, esto es $\bar{Y}_{I}^{c}=\bar{X}_{I} * \widehat{\beta}_{N}$, para expresar la brecha salarial de la siguiente manera: 


$$
\begin{gathered}
\Delta^{\mu}=E\left(X \mid d_{i}=1\right) * \beta_{I}-E\left(X \mid d_{i}=1\right) * \beta_{N}+E\left(X \mid d_{i}=1\right) * \beta_{N}-E\left(X \mid d_{i}=0\right) * \beta_{N} \\
=E\left(X \mid d_{i}=1\right) *\left(\beta_{I}-\beta_{N}\right)+\left[E\left(X \mid d_{i}=1\right)-E\left(X \mid d_{i}=0\right)\right] * \beta_{N} \\
=\Delta_{S}^{\mu}+\Delta_{X}^{\mu}
\end{gathered}
$$

Donde el segundo término en la ecuación $(6), \Delta_{X}^{\mu}$, es la parte de la brecha que refleja puramente diferencias en dotaciones de características observables determinantes del ingreso entre nativos e inmigrantes, generalmente se lo denomina efecto características. En tanto, el primer término, $\Delta_{S}^{\mu}$, mantiene las características constantes y refleja la diferencia en la forma en que son remuneradas, a este término se lo denomina generalmente efecto estructura o coeficientes. Reemplazando el valor esperado de las variables independientes por las medias muestrales y los parámetros de la ecuación salarial por sus estimadores, obtenemos que:

$$
\begin{gathered}
=\bar{X}_{N} *\left(\widehat{\beta}_{I}-\widehat{\beta}_{N}\right)+\left(\bar{X}_{N}-\bar{X}_{I}\right) * \widehat{\beta}_{N} \\
=\widehat{\Delta}_{S}^{\mu}+\widehat{\Delta}_{X}^{\mu}
\end{gathered}
$$

Si bien la descomposición planteada por Oaxaca- Blinder da una idea clara de las fuentes de la brecha salarial entre los grupos, sólo lo hace en un punto de la distribución del ingreso (en la media), sin contemplar qué ocurre en otros puntos de la distribución.

La ventaja que tiene la metodología anterior es que al enfocarse en los ingresos promedio, permite descomponer la brecha bruta de ingresos no condicionales haciendo uso de la Ley de Esperanzas Iteradas (LEI) ${ }^{5}$, para obtener el ingreso promedio contrafáctico no condicional sólo a partir de los coeficientes estimados por mínimos cuadrados y las medias muestrales. Si quisiéramos explorar otros puntos de la distribución del ingreso, la descomposición se vuelve más compleja ya que como

\footnotetext{
${ }^{5}$ La Ley de Esperanzas Iteradas provee un camino alternativo para calcular las esperanzas. Nos dice que para computar el valor esperado de $\mathrm{Y}$ podemos proceder directamente (calcular $E(Y))$ o indirectamente, primero condicionando a $Y$ en alguna variable, y después calculando la esperanza de su esperanza. Esto es, $E(Y)=E[E(Y \mid X)]$
} 
no se cumple la LEI hay que buscar otra manera de obtener un contrafáctico de la distribución no condicional.

Para poder analizar cómo se mueven las diferencias de salario a medida que avanzamos en la distribución de ingresos y suplir la dificultad mencionada anteriormente, Melly B. (2006), propone un estimador de la función de distribución incondicional, que luego es usada para descomponer diferencias en distintos puntos de la distribución, análogamente a la descomposición de Oaxaca- Blinder. El método se basa en la estimación de la función de distribución de salarios condicional utilizando una regresión por cuantiles y luego integrando en todo el rango de covariables para obtener una distribución no condicional y poder estimar el contrafáctico necesario para la descomposición de la brecha.

Para ello, parte una ecuación de salarios similar a la (3) y sigue a Koenker y Bassett (1978) en donde:

$$
F_{Y(g)}^{-1}\left(\tau \mid x_{i}\right)=x_{i} * \beta(\tau), \forall \tau \in(0,1)
$$

Donde, $F_{Y(g)}\left(\tau \mid x_{i}\right)$ representa la distribución acumulada de la variable aleatoria $Y$ condicional en $X$ para el grupo $g, F_{Y(g)}^{-1}(\tau)$ representa la inversa de la función de distribución evaluada en el cuantil $\tau$ y $F_{Y(g)}^{-1}\left(\tau \mid x_{i}\right)$ es la inversa de la función acumulada de distribución de $Y$ evaluada en $\tau$ dado $X=x_{i}$ o también denominada función cuantílica condicional, y el cuantil $\tau$ es un número del soporte de la distribución del ingreso tal que la probabilidad de que ocurran valores menores es $\tau$. Es decir, cuando $\tau=0,5, q(0,5)$ es un valor del soporte de la distribución de $Y$ que deja a la izquierda la mitad de la distribución y es conocido como la mediana de $Y$. Los autores demuestran que $\beta(\tau)$ puede ser estimado por:

$$
\widehat{\beta_{g}}(\tau)=\operatorname{argmin} \frac{1}{N} \sum_{i=1}^{N}\left(Y_{i}-x_{i} \beta\right)\left(\tau-\mathbb{1}\left(Y_{i} \preceq x_{i} \beta\right)\right)
$$

$\beta_{g}(\tau)$ se interpreta como el efecto que tiene un cambio marginal en $x$ sobre el 
$\tau$-esimo cuantil condicional de la distribución de $Y$ para el grupo $g$. Notar que este coeficiente depende explícitamente de $\tau$, por lo que $x$ puede tener un efecto distinto para los diferentes cuantiles de la distribución de $Y$.

Entonces, el cuantil condicional $\tau$ de $Y(g)$ dado $X_{i}$ es consistentemente estimado por $x_{i}^{\prime} \widehat{\beta_{g}}(\tau)$ y teóricamente, es fácil estimar la función de distribución condicional invirtiendo la función cuantílica condicional (ecuación (8)). Sin embargo, esta función estimada no es necesariamente monótona ${ }^{6}$, por lo tanto puede no ser invertible. Para resolver esto, se debe considerar la siguiente propiedad de la función de distribución condicional evaluada en $q$ (donde $q$ es un punto de la distribución del ingreso):

$$
F_{Y(g)}\left(q \mid X_{i}\right)=\int_{0}^{1} \mathbb{1}\left(F_{Y(g)}^{-1}\left(\tau \mid X_{i}\right) \leq q\right) \partial \tau=\int_{0}^{1} \mathbb{1}\left(x_{i} \beta_{g}(\tau) \leq q\right) \partial \tau
$$

Entonces, un estimador natural de la distribución condicional de $Y(g)$ dado $X_{i}$ en $q$ está dado por:

$$
\widehat{F}_{Y(g)}\left(q \mid X_{i}\right)=\int_{0}^{1} \mathbb{1}\left(x_{i} \widehat{\beta}_{g}(\tau) \leq q\right) \partial \tau=\sum_{j=1}^{j}\left(\tau_{j}-\tau_{j-1}\right) \mathbb{1}\left(x_{i} \widehat{\beta}_{g}\left(\tau_{j}\right) \leq q\right)
$$

Esto implica que podemos estimar la función de distribución incondicional, simplemente integrando en el rango de las covariables:

$$
\widehat{F}_{Y(g)}(q \mid G=g)=\int \widehat{F}_{Y(g)}(q \mid x) \partial F_{X}(x \mid G=g)=n_{g}^{-1} \sum_{i: G_{i}=g} \widehat{F}_{Y(g)}\left(q \mid X_{i}\right)
$$

Usualmente, estamos más interesados en la función cuantílica incondicional que en la función de distribución incondicional. La principal importancia de este estimador es la posibilidad de simular la distribución contrafactual que puede ser usada para descomponer diferencias en las distribuciones de dos grupos. Entonces, un estimador natural del $\theta$-ésimo cuantil de la distribución incondicional de $Y$ es:

\footnotetext{
${ }^{6} \tau_{j} \preceq \tau_{k}$ no significa que $x_{i} \widehat{\beta}\left(\tau_{j}\right) \preceq x_{i} \widehat{\beta}\left(\tau_{k}\right)$
} 


$$
\widehat{q}_{(g)}(\theta)=\inf \left\{q: n_{g}^{-1} \sum_{i: G_{i}=g} \widehat{F}_{Y(g)}\left(q \mid X_{i}\right) \geq \theta\right\}
$$

Dada la dificultad de estimar una varianza asintótica, la inferencia se hará por el procedimiento de bootstrap. El contrafactual se define como el $\theta$-ésimo cuantil de la distribución incondicional de $Y$ que observaríamos en los nativos si tuvieran los retornos salariales de los inmigrantes. Esto es:

$$
\widehat{q}_{(c)}(\theta)=\inf \left\{q: n_{N}^{-1} \sum_{i: G_{i}=N} \widehat{F}_{Y(I)}\left(q \mid X_{i}\right) \geq \theta\right\}
$$

Por lo tanto, la descomposición entre los dos grupos en el cuantil $\theta$-ésimo de la distribución incondicional de salarios es:

$$
\begin{gathered}
\widehat{q}_{N}(\theta)-\widehat{q}_{I}(\theta)=\left[\widehat{q}_{N}(\theta)-\widehat{q}_{C}(\theta)\right]+\left[\widehat{q}_{C}(\theta)-\widehat{q}_{I}(\theta)\right] \\
=\widehat{\Delta}_{S}^{q}+\widehat{\Delta}_{X}^{q}
\end{gathered}
$$

Donde el primer corchete representa el efecto de los cambios en los coeficientes y el segundo es el efecto de los cambios en la distribución de las características. Al igual que en la metodología de O-B se logra una descomposición en la que se puede diferenciar, $\widehat{\Delta}_{S}^{q}$, que es la brecha salarial debido al efecto coeficientes (diferencias en los retornos de iguales características en individuos de ambos grupos) y la brecha salarial debido al efecto características, $\widehat{\Delta}_{X}^{q}$, para cada uno de los cuantiles de la distribución incondicional.

\section{Descripción de la muestra}

El trabajo utiliza datos de la Encuesta Permanente de Hogares (EPH) realizada y publicada por el Instituto de Estadísticas y Censos de Argentina (INDEC), 
correspondientes al segundo trimestre de cada año, para el período 2004-2015. La encuesta proporciona información para 31 aglomerados urbanos, cuya cobertura es en promedio el $70 \%$ de la población urbana del país.

La muestra comprende a individuos entre 15 y 65 años y a los efectos de este trabajo, se clasifica a la población en nativa e inmigrante (es decir, no nacidos en Argentina). Mientras que la población nativa representa el $94 \%$ de la muestra, la población inmigrante representa solo el $6 \%$ restante.

En la Figura A del anexo se encuentra el mapa con la distribución de los inmigrantes en el territorio nacional, estimada en base a la población cubierta por la EPH (las áreas del mapa con tonalidad oscura representan los 31 aglomerados). Se observa una clara concentración de la población inmigrante (mas del 80\%) entre la Provincia y Ciudad de Buenos Aires. Muy por debajo le siguen Córdoba y Mendoza ambas con una proporción de $2.4 \%$. Por otro lado, en el Cuadro A del apéndice se muestra la distribución de los inmigrantes según país de origen: más del $60 \%$ provienen de Paraguay, Bolivia y Perú, otro $30 \%$ se compone con personas nacidas en Chile, Uruguay, Italia, España, Brasil y Colombia, y el resto, principalmente por inmigrantes provenientes de Venezuela, Estados Unidos, China y Taiwán.

Los Cuadros 1 y 2 proveen información de las características sociales, demográficas y laborales de la muestra para la población ocupada. Adicionalmente, se muestran las características sociales y demográficas de la muestra completa en el Cuadro B del anexo. Se divide el período analizado en 3 subperíodos (2004-2007, 2008-2011, 2012-2015), tomando como subperíodo un pool de datos correspondientes a los años seleccionados, esto se realiza con el objetivo de visualizar la evolución de las variables en el tiempo.

Observando el cuadro 1 se advierte que la población ocupada nacida en Argentina presenta mayor nivel de educación en promedio que los provenientes de otros países para todos los períodos, con una proporción más alta de individuos con estudios universitarios y secundarios completos. Aun así, se logra una mejora educativa 
reflejada en el aumento de la proporción de individuos con estudios universitarios completos a medida que avanza el tiempo, tanto para la población nativa como para los inmigrantes. Para los tres subperíodos, el grupo inmigrante tiene una edad promedio mayor que el grupo de los nativos(entre 2 y 5 años más que los nativos según el período).

En cuanto a la ubicación geográfica por regiones, la mayoría de la población se encuentra concentrada en el Gran Buenos Aires (GBA). Para el grupo de los nativos, GBA concentra la mitad de la población en el último periodo, con una disminución de 3 puntos porcentuales desde el 2004. Mientras que para el grupo de inmigrantes GBA concentra más del $75 \%$ de la población para los tres períodos.

Por otro lado, si comparamos el cuadro 1 con el cuadro B (presentado en el anexo) se desprende que hay más mujeres que hombres en la muestra, pero esta proporción cambia si consideramos al subgrupo de personas ocupadas, lo cual refleja la diferencia en la tasa de empleo entre hombres y mujeres para todos los períodos. Luego, el último periodo es el que presenta menor proporción de población desocupada tanto para nativos como para inmigrantes, la tasa de ocupación para los inmigrantes ha aumentado en mayor proporción que para los nativos. ${ }^{7}$

En el cuadro 2 se presentan las características laborales para la submuestra de individuos ocupados. Como puede observarse ha habido una evolución favorable de la tasa de informalidad para inmigrantes durante todo el período, disminuyendo 10 puntos porcentuales. Aun así casi el $35 \%$ de los ocupados inmigrantes sigue trabajando de manera informal, porcentaje mayor que el de los nativos. ${ }^{8}$

\footnotetext{
${ }^{7}$ Según el INDEC se define como población ocupada al conjunto de personas que tiene por lo menos una ocupación. Operacionalmente se delimita como tal a la población que, en el período específico denominado semana de referencia, ha trabajado por lo menos una hora. Por el contrario, la población desocupada es el conjunto de personas que, sin tener ningún trabajo, buscaron uno en forma activa en las últimas cuatro semanas. Población inactiva es conjunto de personas que no tienen trabajo ni lo buscan activamente.

${ }^{8} \mathrm{~A}$ los efectos del presente trabajo, definimos que un trabajador es informal cuando no le realizan descuentos jubilatorios en su trabajo.
} 
Cuadro 1: Características sociales y educativas de los ocupados.

\begin{tabular}{lrrrrrr}
\hline \multirow{2}{*}{ Variables } & \multicolumn{2}{c}{$\mathbf{2 0 0 4}-\mathbf{2 0 0 7}$} & \multicolumn{2}{c}{$\mathbf{2 0 0 8 - 2 0 1 1}$} & \multicolumn{2}{c}{$\mathbf{2 0 1 2}-\mathbf{2 0 1 5}$} \\
& Nativos & Inmigrantes & Nativos & Inmigrantes & Nativos & Inmigrantes \\
\hline Hombre & $58 \%$ & $-0.020(0.013)$ & $58 \%$ & $-0.049^{* * *}(0.014)$ & $58 \%$ & $-0.022^{*}(0.013)$ \\
Edad & 38 & $4.738^{* * *}(0.325)$ & 39 & $2.566^{* * *}(0.359)$ & 39 & $3.169^{* * *}(0.303)$ \\
GBA & $55 \%$ & $0.210^{* * *}(0.008)$ & $53 \%$ & $0.260^{* * *}(0.008)$ & $51 \%$ & $0.273^{* * *}(0.008)$ \\
NOA & $9 \%$ & $-0.059^{* * *}(0.002)$ & $9 \%$ & $-0.067^{* * *}(0.002)$ & $10 \%$ & $-0.073^{* * *}(0.002)$ \\
NEA & $4 \%$ & $-0.023^{* * *}(0.002)$ & $5 \%$ & $-0.030^{* * *}(0.001)$ & $5 \%$ & $-0.033^{* * *}(0.001)$ \\
CUYO & $6 \%$ & $-0.028^{* * *}(0.003)$ & $6 \%$ & $-0.032^{* * *}(0.002)$ & $7 \%$ & $-0.040^{* * *}(0.002)$ \\
Pampeana & $23 \%$ & $-0.129^{* * *}(0.006)$ & $24 \%$ & $-0.148^{* * *}(0.005)$ & $24 \%$ & $-0.141^{* * *}(0.006)$ \\
Patagonica & $3 \%$ & $0.029^{* * *}(0.002)$ & $3 \%$ & $0.017^{* * *}(0.002)$ & $4 \%$ & $0.013^{* * *}(0.002)$ \\
Primaria Completa & $39 \%$ & $0.085^{* * *}(0.013)$ & $36 \%$ & $0.081^{* * *}(0.014)$ & $34 \%$ & $0.040^{* * *}(0.012)$ \\
Secundaria Completa & $36 \%$ & $-0.042^{* * *}(0.012)$ & $38 \%$ & $-0.024^{*}(0.013)$ & $40 \%$ & $0.000(0.013)$ \\
Universitaria Completa & $19 \%$ & $-0.091^{* * *}(0.007)$ & $21 \%$ & $-0.094^{* * *}(0.008)$ & $22 \%$ & $-0.091^{* * *}(0.008)$ \\
\hline
\end{tabular}

Notas: errores estándar robustos entre paréntesis, *** significativo al $1 \%, * *$ significativo al $5 \%, *$ significativo al $10 \%$. La columna"nativos" presenta el valor medio de cada variable para el grupo poblacional nativos mientras que la columna "inmigrante" muestra a diferencia del grupo poblacional inmigrante con respecto a la media de los nativos.

Por otro lado, el $70 \%$ de los inmigrantes está concentrado en actividades industriales, comerciales, de construcción y servicio doméstico, en cambio los nativos tienen más del $50 \%$ de su actividad en el sector servicios comparado con, aproximadamente, un $30 \%$ de los inmigrantes. En cuanto a la calificación ocupacional, casi el $85 \%$ de los inmigrantes se encuentra en empleos no calificados o desempeñando tareas de operario, mientras que dicho porcentaje para los nativos asciende a $73 \%$ para el último período. Adicionalmente, al igual que los argentinos, la mayoría de los inmigrantes trabajan como empleados, aun así el grupo de inmigrantes, posee mayor proporción de población trabajando como cuenta propia que el grupo de nativos. 
Cuadro 2: Características laborales de los ocupados.

\begin{tabular}{lrrrrrr}
\hline \multirow{2}{*}{ Variables } & \multicolumn{2}{c}{$\mathbf{2 0 0 4}-\mathbf{2 0 0 7}$} & \multicolumn{2}{c}{$\mathbf{2 0 0 8 - 2 0 1 1}$} & \multicolumn{2}{c}{$\mathbf{2 0 1 2}-\mathbf{2 0 1 5}$} \\
& Nativos & Inmigrantes & Nativos & Inmigrantes & Nativos & Inmigrantes \\
\hline Informal & $33 \%$ & $0.114^{* * *}(0.013)$ & $27 \%$ & $0.131^{* * *}(0.014)$ & $25 \%$ & $0.088^{* * *}(0.012)$ \\
Patrón & $4 \%$ & $0.018^{* * *}(0.006)$ & $4 \%$ & $0.003(0.005)$ & $4 \%$ & $0.007(0.005)$ \\
Cuenta propia & $19 \%$ & $0.081^{* * *}(0.011)$ & $18 \%$ & $0.046^{* * *}(0.011)$ & $18 \%$ & $0.076^{* * *}(0.011)$ \\
Empleado & $78 \%$ & $-0.099^{* * *}(0.012)$ & $78 \%$ & $-0.049^{* * *}(0.012)$ & $78 \%$ & $-0.083^{* * *}(0.012)$ \\
Agro y minas & $1 \%$ & $0.001(0.003)$ & $1 \%$ & $-0.007^{* * *}(0.002)$ & $1 \%$ & $-0.003^{* *}(0.001)$ \\
Industria & $14 \%$ & $0.030^{* * *}(0.010)$ & $13 \%$ & $0.029^{* * *}(0.010)$ & $13 \%$ & $0.023^{* *}(0.009)$ \\
Construcción & $8 \%$ & $0.088^{* * *}(0.010)$ & $8 \%$ & $0.091^{* * *}(0.011)$ & $9 \%$ & $0.097^{* * *}(0.010)$ \\
Comercio & $19 \%$ & $0.022^{* *}(0.010)$ & $19 \%$ & $0.005(0.011)$ & $17 \%$ & $0.011(0.010)$ \\
Servicio doméstico & $7 \%$ & $0.097^{* * *}(0.009)$ & $7 \%$ & $0.104^{* * *}(0.010)$ & $7 \%$ & $0.103^{* * *}(0.009)$ \\
Servicios & $50 \%$ & $-0.235^{* * *}(0.011)$ & $51 \%$ & $-0.212^{* * *}(0.012)$ & $52 \%$ & $-0.226^{* * *}(0.011)$ \\
Profesionales & $9 \%$ & $-0.032^{* * *}(0.006)$ & $10 \%$ & $-0.038^{* * *}(0.006)$ & $9 \%$ & $-0.036^{* * *}(0.006)$ \\
Técnicos & $17 \%$ & $-0.051^{* * *}(0.008)$ & $19 \%$ & $-0.081^{* * *}(0.008)$ & $18 \%$ & $-0.073^{* * *}(0.007)$ \\
Operativos & $50 \%$ & $0.017(0.013)$ & $49 \%$ & $0.037^{* * *}(0.014)$ & $52 \%$ & $0.022^{*}(0.013)$ \\
No calificados & $23 \%$ & $0.069^{* * *}(0.012)$ & $22 \%$ & $0.085^{* * *}(0.013)$ & $21 \%$ & $0.089^{* * *}(0.012)$ \\
\hline
\end{tabular}

Notas: errores estándar robustos entre paréntesis, $* * *$ significativo al $1 \%, * *$ significativo al $5 \%, *$ significativo al $10 \%$. La columna"nativos" presenta el valor medio de cada variable para el grupo poblacional nativos mientras que la columna "inmigrante" muestra a diferencia del grupo poblacional inmigrante con respecto a la media de los nativos.

En base a estos resultados, en la siguiente sección se analiza cuán mayor o menor es la probabilidad de los inmigrantes de encontrarse empleados en determinado sector de actividad/nivel de calificación ocupacional que un nativo, en relación a otro sector/calificación ocupacional, controlando por distintas características que también podrían estar correlacionadas con esta opción. 


\section{Resultados}

\subsection{Segmentación}

Siguiendo a Elliott y Lindley (2008) se comienza el análisis de segregación con una comparación de la probabilidad de que un individuo se encuentre empleado en cierto sector de actividad o empleo con determinada calificación ocupacional para los dos grupos poblacionales, condicional a un vector de características $x_{i}$ que incluye variables de capital humano y características socioeconómicas. En los Cuadros 3 y 4 , se presentan los resultados un modelo logit multinomial, donde se muestra cómo cambia la probabilidad de pertenecer a cualquiera de las calificaciones ocupacionales tenidas en cuenta: profesional, técnico, operario y no calificado (Cuadro 4) o sector de actividad: agricultura y minería, industria, construcción, comercio, servicio doméstico, y servicios (Cuadro 3) de acuerdo a la condición de origen (inmigrante versus nativo). También se incluyen otras variables como las educativas para evaluar su influencia en las oportunidades laborales. En los cuadros se presentan los efectos marginales calculados como la diferencia entre las probabilidades predichas de la variable y la categoría base para una persona con las mismas características (evaluadas en la media).

Este análisis tiene la finalidad de exponer si alguno de estos grupos presenta diferencias en cuanto a sus oportunidades laborales, es decir, si el hecho de ser inmigrante influye en las posibilidades de conseguir algún puesto de trabajo o posicionarse en un sector de actividad específico.

En la variable de origen, la categoría base es nativo, por lo tanto un coeficiente positivo nos indica una mayor probabilidad de los inmigrantes que sus contrapartes nativos de caer en alguna calificación ocupacional o sector de actividad. Consistente con el análisis del cuadro 2, si evaluamos los sectores de actividad, casi todos los coeficientes para la variable inmigrante son positivos indicando que los inmigrantes tienen más probabilidades que los nativos de caer en cualquiera de los sectores de 
actividad expuestos en relación al sector agro y minas, exceptuando las actividades incluidas en servicios. Las actividades que poseen mayor diferencia de probabilidad son aquellas en los sectores de Comercio y Servicio doméstico, es decir, el hecho de ser inmigrante aumenta su probabilidad predicha de estar empleado tanto en comercio como en servicio doméstico alrededor 4 puntos porcentuales, con respecto al sector omitido y controlando por un amplio set de características. Estos resultados están en concordancia con los presentados en la tabla 2, en donde la diferencia de medias incondicional con los nativos para todos los sectores de actividad es positiva.

El Cuadro 4, presenta el mismo análisis para las calificaciones ocupacionales. Se encuentra que, el hecho de ser inmigrante, aumenta la probabilidad de caer en empleos como operario y no calificados en relación a la categoría omitida que es profesional. En cuanto a la educación, la probabilidad de tener un empleo no calificado, en relación a un empleo con calificación profesional, es menor para aquellos que tienen algún tipo de educación formal, y esta diferencia aumenta cuanto más alto es el nivel educativo.

Cuadro 3: Efectos marginales de un modelo logit multinomial para sector de actividad.

\begin{tabular}{lccccc}
\hline Variables & Industria & Construcción & Comercio & Doméstico & Servicios \\
\hline Inmigrante & $0.001^{* *}(0.090)$ & $0.001^{* * *}(0.088)$ & $0.041^{* * *}(0.088)$ & $0.038^{* * *}(0.103)$ & $-0.085^{* * *}(0.087)$ \\
Primaria completa & $-0.000^{* * *}(0.057)$ & $-0.000^{* * *}(0.054)$ & $-0.015^{* * *}(0.054)$ & $-0.017^{* * *}(0.069)$ & $0.045^{* * *}(0.053)$ \\
Secundaria completa & $-0.000^{* * *}(0.061)$ & $-0.001^{* * *}(0.058)$ & $-0.029^{* * *}(0.058)$ & $-0.052^{* * *}(0.078)$ & $0.103^{* * *}(0.057)$ \\
Universitario completo & $-0.001^{* * *}(0.073)$ & $-0.001^{* * *}(0.074)$ & $-0.093^{* * *}(0.069)$ & $-0.059^{* * *}(0.109)$ & $0.171^{* * *}(0.067)$ \\
Observaciones & 258,229 & 258,229 & 258,229 & 258,229 & 258,229 \\
\hline
\end{tabular}

Notas: errores estándar robustos entre paréntesis, ${ }^{* *}$ significativo al $1 \%, * *$ significativo al $5 \%, *$ significativo al $10 \%$. Adicionalmente se controla por edad, edad al cuadrado, sexo, antiguedad (en años), regiones, estado civil, categoría ocupacional y dummies de años. La categoría base de la variable dependiente es Agro y minas. 
Cuadro 4: Efectos marginales de un modelo logit multinomial para la calificación ocupacional.

\begin{tabular}{lccc}
\hline Variables & Técnico & Operario & No calificado \\
\hline Inmigrante & $-0.036(0.055)$ & $0.017^{* * *}(0.057)$ & $0.024^{* * *}(0.065)$ \\
Primaria completa & $0.100^{* * *}(0.146)$ & $-0.036^{* * *}(0.153)$ & $-0.099^{* * *}(0.155)$ \\
Secundaria completa & $0.279^{* * *}(0.144)$ & $-0.163^{* * *}(0.152)$ & $-0.232^{* * *}(0.153)$ \\
Universitario completo & $0.302^{* * *}(0.144)$ & $-0.545^{* * *}(0.152)$ & $-0.258^{* * *}(0.156)$ \\
Agro y minas & $-0.102^{* * *}(0.089)$ & $0.094^{* * *}(0.095)$ & $0.023^{* * *}(0.104)$ \\
Industria & $-0.119^{* * *}(0.040)$ & $0.199^{* * *}(0.040)$ & $-0.059^{* * *}(0.045)$ \\
Construcción & $-0.133^{* * *}(0.051)$ & $0.082^{* * *}(0.053)$ & $0.074^{* * *}(0.056)$ \\
Comercio & $-0.156^{* * *}(0.038)$ & $-0.017^{* * *}(0.041)$ & $0.204^{* * *}(0.043)$ \\
Doméstico & $-0.172^{* * *}(0.495)$ & $-0.606^{* * *}(0.482)$ & $0.809^{* * *}(0.475)$ \\
Observaciones & 261,535 & 261,535 & 261,535 \\
\hline
\end{tabular}

Notas: errores estándar robustos entre paréntesis, *** significativo al $1 \%, * *$ significativo al $5 \%$, $*$ significativo al $10 \%$. Adicionalmente se controla por edad, edad al cuadrado, sexo, antiguedad, regiones, estado civil, categoría ocupacional y años. La categoría base de la variable dependiente es profesional.

\subsection{Diferencia salarial y descomposiciones}

Hasta el momento hemos encontrado que el grupo poblacional de los inmigrantes tiene características que los diferencia del grupo de los nativos, tanto sociales como laborales. En la siguiente subsección se pretende investigar si esta diferencia también se evidencia a nivel salarial y si son las diferencias individuales encontradas anteriormente las que explican el nivel de salarios.

Para ello, se realiza una regresión del logaritmo del salario horario de la ocupación principal en la variable inmigrante. El coeficiente asociado a la variable inmigrante indica, en términos porcentuales, cuánto mayor o menor es el salario promedio de un inmigrante en relación al de un nativo. Cada fila del Cuadro 5 muestra el resultado de una regresión diferente agregando sucesivos controles ${ }^{9}$.

\footnotetext{
${ }^{9}$ Los salarios se encuentran expresados a valores constantes del año 2004. Para ello se utilizó un
} 
Cuadro 5: Regresiones para el logaritmo del salario horario.

\begin{tabular}{lcc}
\hline Variables & Coef. de inmigrante & $R^{2}$ - ajustado \\
\hline$(1)$ & $-0.167^{* * *}(0.011)$ & 0.002 \\
$(2)=(1)+$ Años & $-0.172^{* * *}(0.011)$ & 0.082 \\
$(3)=(2)+$ Demográficas y educativas & $-0.098^{* * *}(0.010)$ & 0.276 \\
$(4)=(3)+$ Laborales & $-0.041^{* * *}(0.010)$ & 0.344 \\
$(5)=(4)+$ Regionales & $-0.104^{* * *}(0.010)$ & 0.377 \\
\hline
\end{tabular}

Notas: errores estándar robustos entre paréntesis, *** significativo al $1 \%$, ** significativo al $5 \%$, $*$ significativo al $10 \%$. (1) Incluye solo la variable inmigrante, (2) agrega dummies de años (año base 2004), (3) agrega sexo, edad, edad al cuadrado, nivel de educación y estado civil, (4) controla adicionalmente por categoría ocupacional, sector de actividad y calificación ocupacional y (5) agrega controles para las regiones (NOA, NEA, Cuyo, Pampeana y Patagónica). El número de observaciones para las regresiones es 248,933.

Los resultados muestran que aún controlando por variables de características individuales, el salario de los inmigrantes es menor que el de los nativos. La diferencia promedio de salarios incondicional es $15.4 \%$ a favor de los nativos, es decir que los inmigrantes ganan en promedio $15.4 \%$ menos que los individuos nacidos en Argentina. ${ }^{10}$ La diferencia se reduce cuando se controla por características demográficas y educativas y, disminuye aún más cuando se agregan las laborales. Por otro lado, se observa que cuando se incluyen las variables regionales la diferencia salarial vuelve a aumentar, aunque sin alcanzar la diferencia inicial bruta. Por lo tanto, existe una brecha sustancial de salarios, pero gran parte se debe a la desventaja de los inmigrantes en términos de educación, sector de actividad económica y demás variables laborales, una vez que se controla por estas características, el coeficiente asociado a inmigrante pasa a ser de $4 \%$. Lo contrario ocurre cuando incluimos las variables regionales, lo cual es un indicio de que los inmigrantes tienden a localizarse en regiones que tienen salarios promedio mayores, tal es el caso de GBA (ver cuadro C índice de precios combinado (INDEC, CENDA y el IPC congreso).

${ }^{10}$ Se obtiene al calcular el efecto marginal de una variable binaria sobre otra medida en logaritmos de la siguiente manera $e^{\beta}-1$. 
del anexo).

La Figura 3, presenta evidencia adicional de la diferencia salarial, graficando la función de densidad de Kernel del logaritmo del salario horario de la ocupación principal. Se observa que los argentinos tienen un salario más alto que los inmigrantes (la media para los nativos del logaritmo del salario horario es de 1.65 puntos logarítmicos y para los inmigrantes es de 1.48); la función de distribución de los nativos está desplazada hacia la derecha, lo que sugiere que los nativos están en mejor condición que los inmigrantes a lo largo de toda la distribución del ingreso. Adicionalmente, las observaciones de los inmigrantes se concentran en un rango de ingresos levemente más corto, lo que significa una menor dispersión de datos asociada con una menor desigualdad.

Figura 3: Densidad de Kernel

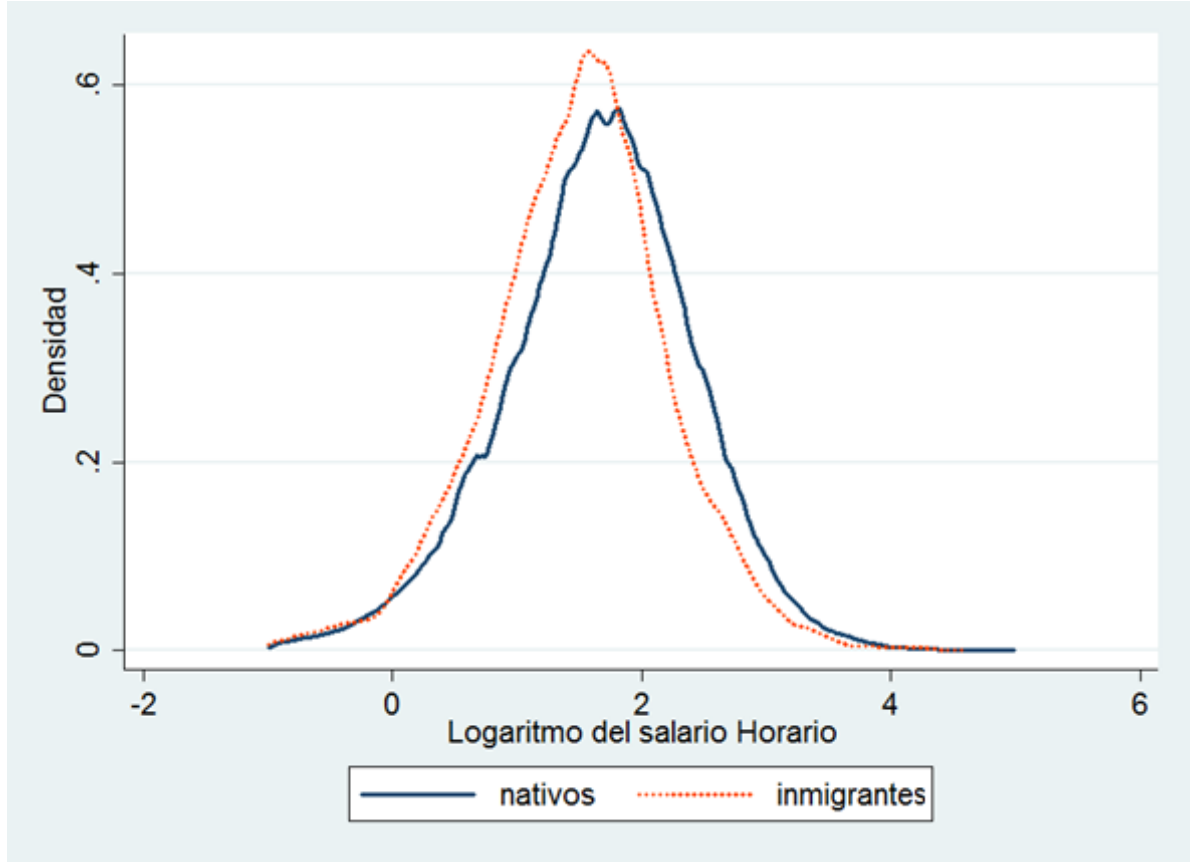

Fuente: elaboración propia en base a EPH. 2004-2015

El signo negativo y la significatividad del coeficiente que acompaña la variable inmigrante en el Cuadro 5, muestra que existe una brecha salarial entre los grupos 
analizados que favorece a los nativos. Para comprender mejor qué parte de la diferencia promedio puede ser explicada por las características obsevables descriptas en la seccion 3 y qué parte se debe a caracteristicas que no es posible observar, el Cuadro 6 presenta los resultados de la descomposición en base a la metodología de Oaxaca-Blinder.

Como se mencionó anteriormente, la brecha del salario promedio entre los dos grupos arroja que un inmigrante gana $15.4 \%$ menos que un nativo. Las columnas 1 y 2 exponen los efectos características y coeficientes de la brecha resultante luego de controlar únicamente por la variable o conjunto de variables indicadas en cada fila. Luego, en las columnas 3 y 4 se muestran todas las estimaciones como porcentaje de la brecha total. ${ }^{11}$ Cabe aclarar, que se utiliza una especificación diferente para cada variable o conjunto de variables expuestas en cada fila del cuadro.

El primer panel controla por características demográficas y educativas; el segundo panel controla por características laborales, las últimas dos líneas de este panel están dedicadas a controlar por la segmentación laboral analizada anteriormente; y por último el tercer panel controla por zona geográfica.

Observando sólo las características demográficas y educativas, las variables de educación logran explicar el $52 \%$ de la brecha, el resto de las variables del panel 1 tienen un efecto contario, aunque en una magnitud mucho menor, manifestando que si no fuera por las diferencias existentes entre nativos e inmigrantes en relación a esas variables, la brecha salarial sería aún mayor; en conjunto, las diferencias entre inmigrantes y nativos en cuanto a estas características logran explicar aproximadamente un $41 \%$ de la brecha observada inicialmente. Si además de características demográficas y educativas, se le suman las características laborales (la categoría ocupacional, condición de informalidad, sectores de actividad y calificación ocupacional), se logra explicar una porción adicional de la brecha, reduciendo así el efecto estructura; casi

\footnotetext{
${ }^{11}$ Para facilitar la exposición, no se muestran los errores estándar de la estimación pero se encuentran disponibles para el lector interesado.
} 
el $90 \%$ de la brecha observada es explicada por características demográficas, sociales y laborales incluidas.

Luego, si controlamos por regiones vemos que la parte explicada de la brecha se reduce, esto está relacionado con que los inmigrantes se encuentran mayormente concentrados en GBA y en promedio los salarios son mayores en GBA que en el resto de las regiones (excepto la Patagonia).

Finalmente, obtenemos que solo el $52 \%$ de la brecha se puede explicar por las variables seleccionadas. Por lo tanto, podríamos inferir que más de la mitad de la diferencia observada se debe a que los grupos tienen diferentes niveles de educación y se seleccionan en empleos informales, con calificaciones ocupacionales de menor paga y en diferentes sectores de actividad económica (segmentación del mercado laboral).

Los resultados obtenidos se encuentran en línea con las conclusiones obtenidas por otros autores. Montoya y Giordano (2012) encuentran que efectivamente los inmigrantes (tanto de países limítrofes como no limítrofes) tienen salarios menores que los nativos para el año 2011 en GBA, y parte de dicha diferencia salarial se debe a la que los inmigrantes están sobrerrepresentados en los sectores de la construcción, la economía doméstica y la venta al por menor, que a su vez son más propensos a la informalidad y la desprotección de la legislación laboral. Elliott y Lindley (2008) encuentran que aún controlando por segregación ocupacional y características socio económicas, sigue habiendo penalidad salarial a favor de los nativos en relación a los inmigrantes en UK.

Con el objetivo de entender si el análisis de las diferencias salariales promedio es representativo para el resto de la distribución, a continuación se realiza la misma descomposición, para distintos cuantiles de la distribución de salarios siguiendo la metodología de Melly (2006), discutida en la sección 2. 
Cuadro 6: Descomposición de la diferencia en el logaritmo del salario horario promedio entre nativos e inmigrantes. Metodología Oaxaca- Blinder.

\section{Participación en la brecha \% en la brecha total \\ Características Coeficientes Características Coeficientes}

(1)

(2)

(3)

\begin{tabular}{|c|c|c|c|c|}
\hline (1)Brecha bruta & 0 & $-0.1670 * * *$ & $0 \%$ & $100 \%$ \\
\hline \multicolumn{5}{|l|}{ Panel 1} \\
\hline Edad (años) & $0.026^{* * *}$ & $-0.193^{* * *}$ & $-16 \%$ & $116 \%$ \\
\hline Sexo (=1 si es hombre) & $0.005^{* * *}$ & $-0.171^{* * *}$ & $-3 \%$ & $103 \%$ \\
\hline Educación & $-0.087^{* * *}$ & $-0.080^{* * *}$ & $52 \%$ & $48 \%$ \\
\hline Estado civil & $0.012^{* * *}$ & $-0.179^{* * *}$ & $-7 \%$ & $107 \%$ \\
\hline$(2)=(1)+$ Demográficas y Educativas & $-0.068^{* * *}$ & $-0.099^{* * *}$ & $41 \%$ & $59 \%$ \\
\hline \multicolumn{5}{|l|}{ Panel 2} \\
\hline$(2)+$ Categoría ocupacional & $-0.081^{* * *}$ & $-0.085^{* * *}$ & $49 \%$ & $51 \%$ \\
\hline$(2)+$ Informal & $-0.095^{* * *}$ & $-0.072^{* * *}$ & $57 \%$ & $43 \%$ \\
\hline (2)+Antiguedad (años) & $-0.068^{* * *}$ & $-0.098^{* * *}$ & $41 \%$ & $59 \%$ \\
\hline (2) + Sector de actividad & $-0.108^{* * *}$ & $-0.058^{* * *}$ & $65 \%$ & $35 \%$ \\
\hline (2)+Calificación ocupacional & $-0.087^{* * *}$ & $-0.079^{* * *}$ & $52 \%$ & $47 \%$ \\
\hline$(3)=(2)+$ Laborales & $-0.148^{* * *}$ & $-0.019^{* * *}$ & $89 \%$ & $11 \%$ \\
\hline \multicolumn{5}{|l|}{ Panel 3} \\
\hline$(3)+\mathrm{NOA}$ & $-0.127^{* * *}$ & $-0.040 * * *$ & $76 \%$ & $24 \%$ \\
\hline$(3)+\mathrm{NEA}$ & $-0.137^{* * *}$ & $-0.030^{* * *}$ & $82 \%$ & $18 \%$ \\
\hline (3)+Cuyo & $-0.142^{* * *}$ & $-0.025^{* * *}$ & $85 \%$ & $15 \%$ \\
\hline (3)+Pampeana & $-0.148^{* * *}$ & $-0.019 * * *$ & $89 \%$ & $11 \%$ \\
\hline (3)+Patagónica & $-0.141^{* * *}$ & $-0.025 * * *$ & $84 \%$ & $15 \%$ \\
\hline$(4)=(3)+$ Regionales & $-0.086^{* * *}$ & $-0.080^{* * *}$ & $52 \%$ & $48 \%$ \\
\hline
\end{tabular}

Notas: errores estándar robustos entre paréntesis, *** significativo al $1 \%$, ** significativo al $5 \%$, * significativo al $10 \%$. El grupo base es el de nativos, esto quiere decir que se compara el salario de los inmigrantes contra el de los nativos, por esta razón se presenta la brecha negativa. Educación se refiere a un conjunto de dummies (primario completo, secundario completo y universitario completo), al igual que estado civil (unido, casado, separado, viudo, soltero), categoría ocupacional (patrón, empleado y cuenta propia), sector de actividad (agro y minas, industria, construcción, comercio, doméstico y servicios) y calificación ocupacional (profesional, técnico, operativo y no calificado). En todos los casos se controla adicionalmente por dummies de años. 
Para ello, se divide la distribución del ingreso en cinco cuantiles. Por ejemplo, el primer cuantil utilizado es $\tau=0.1$ cuyo valor soporte deja a la izquierda de la distribución el $10 \%$ de la población con menores ingresos. El Cuadro 7 muestra los resultados de la descomposición en los cuantiles seleccionados, en el primer panel se expone el efecto características y el efecto coeficientes de la brecha controlando por todas las variables utilizadas para la descomposición O-B; luego, en el segundo panel se muestran las estimaciones como porcentaje de la brecha total.

Como se puede observar, hay un aumento de la brecha a medida que avanzamos en la distribución del ingreso: para el cuantil más alto la brecha es casi 12 puntos porcentuales mayor que para el primer cuantil. No solo aumenta la brecha, sino que la composición entre la parte explicada y no explicada también cambia. Interesantemente, la participación del efecto características en la brecha total presenta una forma de U para los cuantiles seleccionados: tanto en el cuantil más alto como en el más bajo, más del $60 \%$ de la diferencia es explicada por las características de los individuos, mientras que este porcentaje se reduce para cuantiles intermedios, siendo $36 \%$ para el cuantil 0.5. En otras palabras, en la mediana de la distribución del ingreso, casi el $65 \%$ de la brecha salarial no puede ser explicada por las características observables incluidas en el análisis. En la figura B del anexo, se presenta la evolución del coeficiente características a lo largo de la distribución y su participación en la brecha total.

Una posible explicación para este comportamiento radica en que, los cuantiles más bajos de la distribución del ingreso presentan mayor segmentación e informalidad (sobre todo en los sectores de construcción y servicio doméstico), es decir, la explicación de la brecha es alta en este tramo de la distribución gracias a estas características observables. Luego, en los cuantiles más altos, la educación juega un papel importante y como se mencionó anteriormente, los argentinos tienen ventaja en esta característica, esto nos daría un indicio de que en la parte superior de la distribución la educación es la encargada de explicar gran parte de la diferencia salarial. En el 
medio de la distribución, hay mayor diversidad en cuanto a sectores de actividad y nivel de educación, por lo tanto, es posible que otros factores no observables jueguen un rol importante a la hora de definir remuneraciones, o simplemente haya algún componente mayor de discriminación.

La siguiente sección intenta brindar evidencia adicional sobre los determinantes de la diferencia salarial analizada anteriormente, desde la perspectiva de la teoría de la asimilación.

Cuadro 7: Descomposición de la diferencia en el logaritmo del salario horario entre nativos e inmigrantes a lo largo de toda la distribución. Metodología Melly.

\begin{tabular}{lccccc}
\hline & $\tau=0.10$ & $\tau=0.25$ & $\tau=0.50$ & $\tau=0.75$ & $\tau=0.90$ \\
\hline Panel 1 & & & & \\
Brecha bruta & $-0.091^{* * *}(0.003)$ & $-0.131^{* * *}(0.003)$ & $-0.178^{* * *}(0.003)$ & $-0.221^{* * *}(0.003)$ & $-0.230^{* * *}(0.004)$ \\
Características & $-0.066^{* * *}(0.013)$ & $-0.064^{* * *}(0.011)$ & $-0.064^{* * *}(0.012)$ & $-0.095^{* * *}(0.014)$ & $-0.141^{* * *}(0.17)$ \\
Coeficientes & $-0.025^{* *}(0.015)$ & $-0.067^{* * *}(0.011)$ & $-0.114^{* * *}(0.010)$ & $-0.126^{* * *}(0.011)$ & $-0.090^{* * *}(0.013)$ \\
\hline Panel 2 & & & & & \\
Brecha bruta & $-8.7 \%$ & $-12.3 \%$ & $-16.3 \%$ & $-19.8 \%$ & $-20.6 \%$ \\
Características & $73 \%$ & $49 \%$ & $36 \%$ & $43 \%$ & $61 \%$ \\
Coeficientes & $27 \%$ & $51 \%$ & $64 \%$ & $57 \%$ & $39 \%$ \\
\hline
\end{tabular}

Notas: errores estándar robustos entre paréntesis, *** significativo al $1 \%, * *$ significativo al $5 \%$, * significativo al $10 \%$. El grupo base es el de nativos, esto quiere decir que se compara el salario de los inmigrantes contra el de los nativos, por esta razón se presenta la brecha negativa. Se controla por dummies de años (año base 2004), sexo, edad, edad al cuadrado, antiguedad, dummies de eduación, estado civil, categoría ocupacional, informalidad, sector de actividad y calificación ocupacional, adicionalmente agregan controles para las regiones (NOA, NEA, Cuyo, Pampeana y Patagónica). Los errores estándar se calculan por bootstrap, 50 repeticiones.

\subsection{Evidencia de (no) asimilación}

La parte no explicada de la brecha salarial puede deberse a muchos factores, la discriminación es uno de ellos y las características no observables de los individuos son otro, o bien puede deberse a que un individuo todavía no llegó a finalizar el "proceso de asimilación". La presente sección pretende analizar si existe evidencia de falta de asimilación que pueda justificar la parte no explicada de la brecha obtenida 
en la sección anterior.

Nielsen, Rosholm, Smith, y Husted (2004) afirman que cuando los inmigrantes arriban al país receptor, son menos productivos que sus contrapartes nativos (condicionado a su nivel de educación, experiencia, etc.), pero a medida que pasa el tiempo, el salario del inmigrante tiende a converger al salario de los nativos, gracias al perfeccionamiento del lenguaje, a la adquisición de características y comportamientos culturales. De todas formas, en caso de que exista discriminación, la brecha salarial podría no cerrarse completamente con el paso del tiempo. Por lo tanto, es importante distinguir la diferencia transitoria que se puede generar por la falta de asimilación, de la diferencia causada por discriminación, que se genera solo por el hecho de pertenecer al grupo inmigrante.

Dada la restricción de datos impuesta por la utilización de la EPH, no es posible seguir la metodología propuesta por Nielsen et al. (2004) en la que descomponen la brecha en los tres componentes: características observables, características inobservables, y asimilación, mediante la generación de datos de panel con cohortes según los años del inmigrante en el país desde la migración. La EPH no presenta información del año de llegada al país del inmigrante, por lo tanto no se puede dividir a dicha población en cohortes según años de llegada. Para suplir esta falencia y poder examinar si existe evidencia de asimilación en Argentina se seguirá el análisis planteado por Borjas (2015), quien utiliza datos de encuestas y realiza un análisis de corte transversal, comparando la diferencia salarial en relación a los nativos de los inmigrantes que llegaron hace poco con los inmigrantes que poseen mayor tiempo de residencia en Estados Unidos. Si bien esta metodología no permite saber la magnitud que representa la asimilación en la brecha total, se podrá evaluar si este fenómeno existe y si se debe tener en cuenta a la hora de analizar la diferencia salarial entre nativos e inmigrantes en Argentina.

En la Encuesta Permanente de Hogares la única variable que nos da una medida del tiempo de estadía del inmigrante en Argentina es la pregunta "¿Dónde estaba 
hace 5 años?" Con esto, podemos saber si el inmigrante está en Argentina hace más o menos de un quinquenio. En base a esta variable, se crean dos variables binarias: "residencia +5 años", que es igual a uno si el individuo es inmigrante y reside en Argentina hace más de cinco años y "residencia -5 años", que es igual a uno si el individuo es inmigrante y reside en Argentina hace menos de cinco años (la categoría complementaria de estas variables es nativos).

La hipótesis que se intentará evaluar es que, si los inmigrantes que llegan al país atraviesan por un proceso de asimilación, deberíamos esperar que aquellos que están hace más de cinco años en el país, tengan una menor diferencia salarial con respecto a los nativos que aquellos que están hace menos de cinco años.

En el Cuadro 8, se presentan los resultados de las regresiones para el logaritmo del salario horario de la ocupación principal. En las columnas (1) y (2) se realizan las regresiones del logaritmo del salario horario en las variables de residencia controlando por sexo, edad, edad al cuadrado, educación, estado civil, categoría ocupacional, antigüedad, informalidad, sector de actividad, calificación ocupacional, años y regiones, agrupando todos los años. Además, para entender si este efecto cambió en el tiempo, se realiza el mismo análisis pero interactuando la variable de interés (residente +5 años y residente -5 años) con dummies de años (resultados resumidos en la figura B del anexo). Por último, debido a que el idioma es uno de los factores influyentes en el proceso de asimilación (Borjas, 2015) en las columnas (3) y (4), se presenta un análisis similar al presentado en las columnas (1) y (2) pero se tienen en cuenta sólo a inmigrantes que provienen de países cuyo idioma oficial es el español. En este caso se esperaría un proceso de asimilación más inmediato que el que puedan transitar los inmigrantes con idioma distinto.

En principio, este análisis no brinda evidencia a favor de la teoría de asimilación en Argentina. Las regresiones con el pool de datos (columnas 1 y 2 ) muestran que los inmigrantes que residen en Argentina hace más de cinco años cobran en promedio un $7.8 \%$ menos que los Argentinos, mientras que aquellos que tienen menos de cinco 
años de residencia en el país tienen un salario en promedio $6.7 \%$ menor. ${ }^{12}$ Cuando corremos las mismas regresiones adicionando las interacciones por año, podemos ver que la hipótesis se cumple solo para cinco años (2005, 2007, 2010, 2012 y 2015) y los coeficientes en su mayoría no llegan a ser significativos al $10 \%$.

Contrariamente con los resultados anteriores, los coeficientes de las columnas 3 y 4 arrojan evidencia a favor de la teoría de asimilación, los inmigrantes que hablan español y residen hace más de cinco años en Argentina tienen una diferencia salarial con los nativos menor que los inmigrantes que hablan español recién llegados, $8.8 \%$ contra $-11.2 \%$, respectivamente. Esto podría indicarnos que el idioma es una condición necesaria para lograr un proceso de asimilación, los inmigrantes de habla hispana recién llegados, tienen en promedio ingresos menores en relación a los nativos que el total de los inmigrantes, pero luego sus ingresos mejoran en contraposición a lo que ocurre cuando se tiene en cuenta el total de los inmigrantes (todos los idiomas).

Cuadro 8: Regresiones del logaritmo del salario horario en la variable de residencia.

(1)

\begin{tabular}{lcccc}
\hline Residente +5 años & $-0.081^{* * *}(0.010)$ & & $-0.092^{* * *}(0.011)$ & \\
Residente -5 años & & $-0.069^{* * *}(0.030)$ & & $-0.119^{* * *}(0.031)$ \\
& & & & \\
Observaciones & 248,340 & 240,017 & 247,515 & 239,951 \\
$R^{2}$ - ajustado & 0.406 & 0.409 & 0.407 & 0.409 \\
\hline
\end{tabular}

Notas: errores estándar robustos entre paréntesis, *** significativo al $1 \%$, ** significativo al $5 \%$, $*$ significativo al $10 \%$. La variable dependiente de todas las regresiones es el logaritmo del salario horario. En las columnas impares (pares) se regresa una dummy igual a 1 para los inmigrantes que residen hace más (menos) de 5 años y 0 para los nativos. En todas las columnas se controla adicionalmente por sexo, edad, edad al cuadrado, educación, estado civil, antigüedad, informalidad, categoría ocupacional, sector de actividad, calificación ocupacional, regiones y años. En las últimas dos columnas se tienen en cuenta solo los inmigrantes que provienen de países que tienen como lengua oficial el español.

\footnotetext{
${ }^{12}$ Ver nota 10
} 
De todas formas, el indicador de residencia analizado es imperfecto, dado que es posible que cinco años no sea un período suficientemente largo como para insertarse y adicionalmente, el grupo de inmigrantes que llegaron hace más de 5 años contiene tiempos de residencia muy heterogéneos. Entonces, como ejercicio adicional, se intenta separar los inmigrantes que llegaron hace más de 5 años en diferentes cohortes de residencia.

Si bien, como se mencionó antes, no existe información exacta sobre el año de llegada al país, una forma de aproximar el tiempo de residencia del inmigrante es a partir de la muestra de inmigrantes con hijos, en base a la edad de su hijo y su nacionalidad. Por ejemplo, si tiene un hijo argentino podríamos inferir que reside en Argentina hace $x$ años, siendo $x$ la edad de su hijo mayor nacido en el país. Tomaremos este período como un "límite inferior" de su residencia en el país. De la misma manera, si su hijo es inmigrante podemos suponer que llegó a Argentina luego de haber nacido su hijo en el extranjero, por lo tanto la edad de su hijo menor nacido en el país de origen será considerada como un "límite superior" de su residencia en Argentina. Así, se sigue la siguiente regla de asignación de cada inmigrante a una "cohorte de residencia":

1- Si el inmigrante tiene hijos argentinos, se toma como residencia la edad del hijo más grande argentino, suponiendo que tuvo al hijo durante el año que arribó a Argentina.

2- Si tiene un hijo inmigrante, se toma la edad del hijo inmigrante menor como proxi de residencia, suponiendo que vino a Argentina inmediatamente luego de tener al hijo más chico nacido en otro país. ${ }^{13}$

Es importante mencionar que al ser una muestra seleccionada, puede no ser representativa de los inmigrantes en general, ya que para los inmigrantes que respondieron que estaban hace más de cinco años en Argentina se tienen en cuenta solo

\footnotetext{
${ }^{13} \mathrm{En}$ el caso de los inmigrantes que tengan tanto hijos provenientes de otro país como hijos argentinos, se imputa siempre la edad del hijo argentino.
} 
los que tienen descendencia y adicionalmente, aquellos que viven con su(s) hijo(s) en el mismo hogar. Además, ésta es una medida imperfecta del verdadero tiempo de residencia, lo cual conlleva necesariamente un error de medición que va a sesgar los coeficientes hacia cero. ${ }^{14}$ Aun así, se puede interpretar esta estimación como un límite inferior del verdadero parámetro.

De acuerdo a nuestra clasificación, en la cohorte 1 se encuentran los inmigrantes que contestaron que no estaban en el país hace 5 años (por lo tanto se asume un tiempo de residencia menor a cinco años). En las cohortes restantes, se encuentran los inmigrantes que respondieron que estaban en Argentina hace 5 años o más y se les pudo imputar un tiempo de residencia según los supuestos anteriores basados en la edad del hijo, agrupándolos en tres grupos: aquellos con residencia de entre 6 y 10 años, entre 11 y 20 años, y más de 20 años. Al igual que antes, utilizando esta medida alternativa de residencia se puede verificar si es que existe evidencia a favor de la teoría de asimilación en Argentina. En este caso, las primeras cohortes, que corresponden a los inmigrantes con menos años de residencia, deberían tener mayor diferencia salarial en relación a los nativos que las últimas cohortes.

Los resultados se presentan en el Cuadro 9, donde la primera columna presenta la regresión del logaritmo del salario horario en las variables de cohorte controlando por sexo, edad, edad al cuadrado, educación, estado civil, categoría ocupacional, antigüedad, informalidad, sector de actividad, calificación ocupacional, años y regiones, agrupando todos los años. Luego, en las siguientes columnas se presenta la misma regresión pero interactuando las variables de residencia con los años. Tanto en la regresión con el pool de datos (primera columna) como en la regresión con interacciones por año no se encuentra un patrón concreto de asimilación. Mirando

\footnotetext{
${ }^{14}$ Algunos ejemplos en los que no se cumple nuestra asignación de los inmigrantes en las cohortes de residencia son: un inmigrante que vino a Argentina y tuvo a su hijo luego de varios años de residencia, o si tuvo a su hijo en el extranjero y no emigró inmediatamente; puede ocurrir también que haya tenido a su hijo en Argentina, que luego haya vivido en otro país y vuelto recientemente. Al tratar con datos a nivel hogar, puede ser que se le impute la edad del hijo de su pareja y entonces no sería una buena medida del tiempo de residencia del inmigrante.
} 
los coeficientes por año y comparando la primer y última cohorte, solo se cumple en 5 años $(2005,2007,2009,2010$ y 2012) que la diferencia salarial es mayor en la cohorte 1 que en la cohorte 4. Esto se observa en la Figura C del anexo, donde se muestra para cada año la diferencia salarial existente (en \%) para cada cohorte en relación a los nativos.

Por lo tanto, con el análisis realizado, no se observa un cumplimiento de la teoría de asimilación en Argentina. De acuerdo a los resultados obtenidos con la agrupación de inmigrantes en cohortes por tiempo de estadía en el país, los inmigrantes con mayor cantidad de años desde la migración no presentan un acercamiento de su nivel salarial al de los nativos. Es decir, no se observa una dinámica de disminución de la diferencia salarial en relación a la población argentina a medida que transcurre el tiempo de residencia. 
Cuadro 9: Regresiones del logaritmo del salario horario para distintas cohortes de residencia.

\begin{tabular}{|c|c|c|c|c|c|}
\hline & \multirow[t]{3}{*}{ Regresión efecto global } & \multicolumn{4}{|c|}{ Regresión con interacciones por año } \\
\hline & & Cohorte 1 & Cohorte 2 & Cohorte 3 & Cohorte 4 \\
\hline & & $<a 5$ años & $6-10$ años & $11-20$ años & $>a 20$ años \\
\hline Cohorte 1 & $-0.071^{* * *}(0.002)$ & $0.007(0.005)$ & & & \\
\hline Cohorte 2 & $-0.047^{* * *}(0.001)$ & & $-0.188^{* * *}(0.001)$ & & \\
\hline Cohorte 3 & $-0.087^{* * *}(0.001)$ & & & $-0.040^{* * *}(0.001)$ & \\
\hline Cohorte 4 & $-0.084^{* * *}(0.001)$ & & & & $-0.070^{* * *}(0.001)$ \\
\hline Cohorte*año2005 & & $-0.139^{* * *}(0.003)$ & $0.034^{* * *}(0.001)$ & $0.030^{* * *}(0.001)$ & $0.048^{* * *}(0.000)$ \\
\hline Cohorte*año2006 & & $0.088^{* * *}(0.004)$ & $0.287 * * *(0.001)$ & $-0.148^{* * *}(0.000)$ & $-0.053^{* * *}(0.000)$ \\
\hline Cohorte*año2007 & & $-0.272^{* * *}(0.002)$ & $0.195^{* * *}(0.001)$ & $0.031^{* * *}(0.000)$ & $-0.026^{* * *}(0.000)$ \\
\hline Cohorte*año2008 & & $-0.032 * * *(0.003)$ & $0.061^{* * *}(0.002)$ & $-0.100^{* * *}(0.001)$ & $0.005^{* * *}(0.000)$ \\
\hline Cohorte*año2009 & & $-0.121 * * *(0.003)$ & $0.028^{* * *}(0.001)$ & $-0.097^{* * *}(0.001)$ & $-0.044^{* * *}(0.001)$ \\
\hline Cohorte*año2010 & & $-0.240^{* * *}(0.004)$ & $0.161^{* * *}(0.001)$ & $-0.003^{* * *}(0.001)$ & $-0.018^{* * *}(0.001)$ \\
\hline Cohorte*año2011 & & $-0.150 * * *(0.003)$ & $0.092^{* * *}(0.001)$ & $-0.057 * * *(0.001)$ & $-0.103^{* * *}(0.001)$ \\
\hline Cohorte*año2012 & & $-0.162 * * *(0.003)$ & $0.165^{* * *}(0.001)$ & $0.005^{* * *}(0.001)$ & $0.048^{* * *}(0.001)$ \\
\hline Cohorte*año2013 & & $0.124^{* * *}(0.004)$ & $0.139^{* * *}(0.002)$ & $-0.062^{* * *}(0.001)$ & $0.015^{* * *}(0.000)$ \\
\hline Cohorte*año2014 & & $0.114^{* * *}(0.004)$ & $0.213^{* * *}(0.001)$ & $-0.130^{* * *}(0.001)$ & $0.002 * * *(0.000)$ \\
\hline Cohorte*año2015 & & $-0.070 * * *(0.005)$ & $0.264^{* * *}(0.001)$ & $-0.002^{* * *}(0.001)$ & $-0.033^{* * *}(0.000)$ \\
\hline Observaciones & 246,090 & & &, 090 & \\
\hline$R^{2}$ - ajustado & 0.406 & & & 106 & \\
\hline
\end{tabular}

Notas: errores estándar robustos entre paréntesis, $* * *$ significativo al $1 \%, * *$ significativo al $5 \%, *$ significativo al $10 \%$. La variable dependiente de las dos regresiones es el logaritmo del salario horario. La categoría base siempre es nativos y para la regresión con interacciones el año base es 2004. Se controla adicionalmente por sexo, edad, edad al cuadrado, educación, estado civil, antigüedad, informalidad, categoría ocupacional, sector de actividad, calificación ocupacional, regiones y años.

\section{Conclusiones}

La historia de Argentina está marcada por constantes movimientos migratorios, se caracteriza por ser receptor de inmigrantes, pero la composición de las inmigraciones ha cambiado durante la historia del país. Hasta mediados del siglo XX, Argentina se destacó por el papel que jugaron las migraciones internacionales procedentes de 
Europa en el crecimiento, composición y distribución espacial de su población y en la configuración de su fuerza de trabajo, pero en los últimos años los inmigrantes pasaron a ser casi exclusivamente de países limítrofes, de Perú y de otros países de América del Sur buscando mayor estabilidad laboral y mejores condiciones de vida. Argentina es el país de América del Sur no solo con el mayor stock de inmigrantes en términos absolutos sino también como proporción de la población.

Más allá de que sus leyes persigan la igualdad e inclusión social de los inmigrantes, aún persisten situaciones de vulnerabilidad que afectan a los trabajadores migrantes y a sus familias, principalmente las vinculadas con la discriminación y una mayor inserción de este colectivo en empleos del sector informal, con elevado índice de precariedad y menores salarios.

El presente trabajo evalúa dicha vulnerabilidad en el mercado laboral a través de dos enfoques: el primero, intenta descomponer la brecha observada en dos componentes, uno referido a las diferencias en características observables de los individuos y el otro referido a las características inobservables, que puede incluir un componente de discriminación. El segundo, conocido como la teoría de asimilación postula que la diferencia salarial desaparece a medida que el inmigrante transita tiempo de residencia en el país, e intenta evaluar si esa brecha es menor para aquellos inmigrantes que están en el país hace más tiempo.

Los resultados sugieren que efectivamente existe una diferencia salarial entre inmigrantes y nativos. La población inmigrante gana en promedio un $15.4 \%$ menos que la población nativa. Esto se explica en un $52 \%$ por características observables de los individuos como la educación, la informalidad y la segmentación laboral.

Por otro lado, se encuentra que la diferencia salarial abarca toda la distribución del ingreso y se amplía a medida que nos movemos hacia los cuantiles más ricos. Gran parte de la diferencia salarial puede ser explicada por características observables en los dos extremos de la distribución, pero el componente inobservable de la brecha se hace más grande cuando nos movemos desde los extremos hacia el centro. 
Por lo tanto, hay gran parte de la diferencia salarial que no puede ser explicada (que es mayor en la parte media de la distribución del ingreso) y podría ser producto de discriminación como de diferencias en otras características inobservables o simplemente falta de asimilación. De todas formas, con los datos disponibles, tampoco se encuentra evidencia en favor de asimilación en Argentina. Dada la falta de información sobre el año de llegada del inmigrante al país, queda pendiente la profundización de este análisis para futuras investigaciones.

Sin embargo, las implicaciones políticas del trabajo son bastante claras. Los esfuerzos para reducir las desigualdades de ingresos entre los grupos poblacionales deben dirigirse hacia la inserción de los inmigrantes en empleos con mayor calificación y menor informalidad. Adicionalmente, los resultados del trabajo advierten que la diferencia salarial producto de características no observables se amplía en los cuantiles medios de la distribución, por lo tanto se debe revisar y mejorar la legislación contra la discriminación salarial focalizando la atención en la población con medianos ingresos. 


\section{Referencias}

[1] Blinder, A. S. (1973). Wage Discrimination: Reduced Form and Structural Estimates. The Journal of Human Resources , 8(4), 436-455.

[2] Borjas, G. J. (1985). Assimilation, Changes in Cohort Quality, and the Earnings of Immigrants. Journal of Labor Economics, 3(4).

[3] Borjas, G. J. (2015). The Slowdown in the Economic Assimilation of Immigrants: Aging and Cohort Effects Revisited Again. Journal of Human Capital, 9(4), 483517.

[4] Canal-Domínguez, J. F. \& Rodríguez-Gutiérrez, C. (2008). Analysis of wage differences between native and immigrant workers in Spain. Span Econ Rev, 10, $109-134$.

[5] Card, D. (2005). Is the New Inmmigration Really So Bad? The Economic Journal, 115(1), 300-323.

[6] Chiswick, B. R. (1978). The Effect of Americanization on the Earnings of Foreign-born Men. Journal of Political Economy, 86(5), 897-921.

[7] Elliott, R. J. \& Lindley, J. K. (2008). Immigrant Wage Differentials , Ethnicity and Occupational Segregation. Journal of the Royal Statistical Society. Series A (Statistics in Society), 171(3), 645-671.

[8] Hunt, P. (2012). From the Bottom to the Top: a more complete picture of the immigrant-native wage gap in Britain. IZA Journal of Migration, 1, 1-18.

[9] Ma, X. (2016). Determinants of the Wage Gap between Migrants and Local Urban Residents in China: 2002-2013. Modern Economy, 7, 786-798. 
[10] Maurizio, R. (2008). Migraciones Internacionales en Argentina: un análisis de sus determinantes y de su relación con el mercado de trabajo. Santiago de Chile, CEPAL-BID.

[11] Melly, B. (2005). Decomposition of differences in distribution using quantile regression. Labour Economics, 12, 577-590.

[12] Melly, B. (2006). Estimation of Counterfactual Distributions Using Quantile Regression, mimeo.

[13] Montoya, S. \& Giordano, V. (2012). Immigrants wage gap in the Great Buenos Aires labor market : how important are differences in human capital? Documento de trabajo No. 36, Escuela de Economía Francisco Valsecchi, Facultad de Economía de la Universidad Católica Argentina.

[14] Nielsen, H. S., Rosholm, M. \& Smith, N. (2004). An Extended Framework for Analysing Immigrant Wage Gaps. Empirical Economics, 29(4), 855-883.

[15] Oaxaca Ronald. (1973). Male-Female Wage Differentials in Urban Labor Markets. International Economic Review, vol. 14, issue 3, 693-709.

[16] Smith, B. J. P. (2003). Assimilation Across the Latino Generations. The American Economic Review, 93(2), 315-319. 


\section{Anexo}

Figura A-Mapa: distribución de la población inmigrante en Argentina.

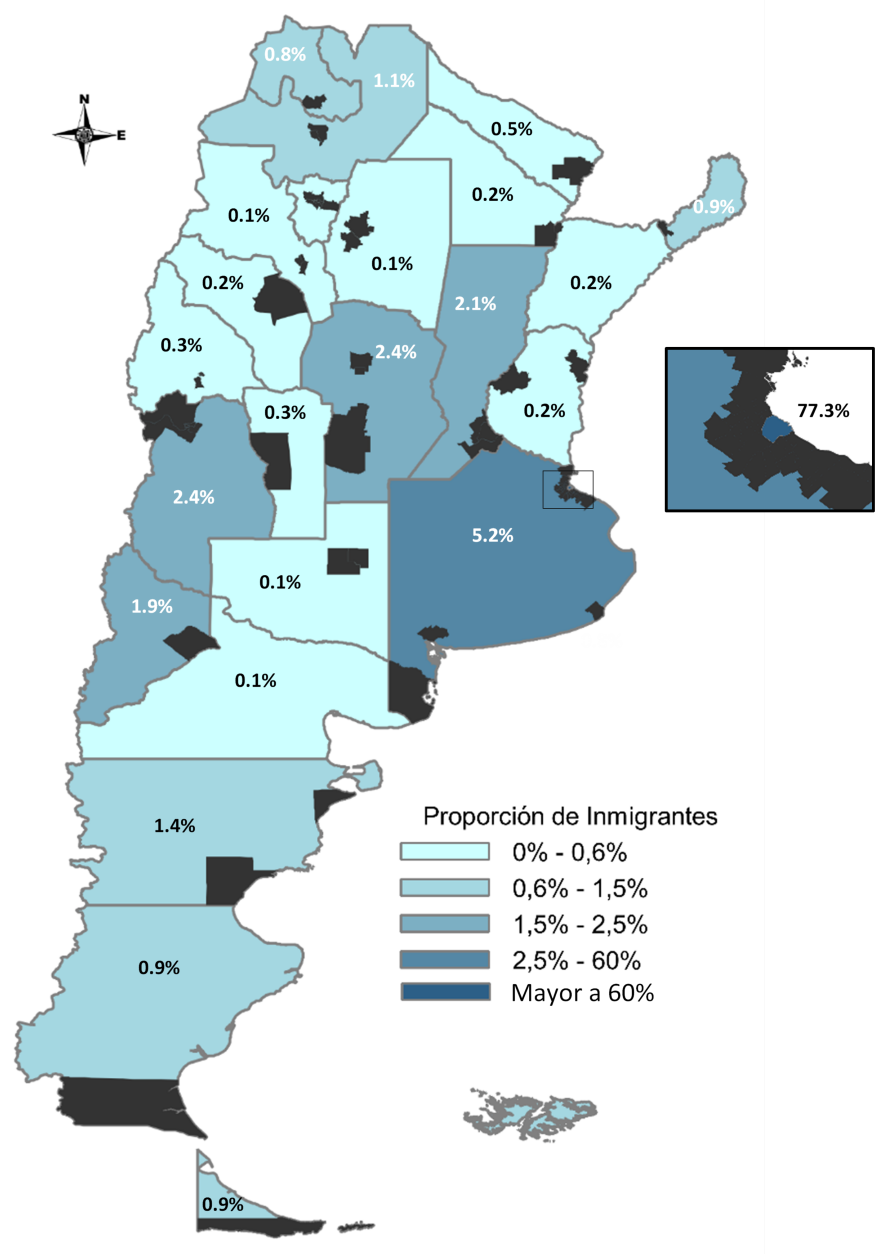

Fuente: elaboración propia en base a EPH. 2004-2015 
Cuadro A-Participación de inmigrantes en Argentina según país de nacimiento. 2004-2015

\begin{tabular}{lclclc}
\hline País & $(\boldsymbol{\%})$ & País & $(\boldsymbol{\%})$ & País & $\mathbf{( \% )}$ \\
\hline Paraguay & 30.5 & Brasil & 1.6 & Afganistan & 0.3 \\
Bolivia & 19.4 & Colombia & 1.0 & Portugal & 0.3 \\
Peru & 13.0 & Venezuela & 0.7 & Corea Republica & 0.3 \\
Chile & 10.3 & Estados Unidos & 0.7 & Francia & 0.3 \\
Uruguay & 9.1 & China & 0.4 & Resto & 3.1 \\
Italia & 5.7 & Taiwan & 0.4 & & \\
España & 2.5 & Ecuador & 0.3 & & \\
\hline
\end{tabular}

Cuadro B-Características sociales y educativas para el total de la muestra.

\begin{tabular}{|c|c|c|c|c|c|c|}
\hline \multirow[t]{2}{*}{ Variables } & \multicolumn{2}{|c|}{$2004-2007$} & \multicolumn{2}{|c|}{ 208-2011 } & \multicolumn{2}{|c|}{$2012-2015$} \\
\hline & Nativos & Inmigranres & Nativos & Inmigrantes & Nativos & Inmigrantes \\
\hline Hombre & $48 \%$ & $-0.027^{* * *}(0.010)$ & $49 \%$ & $-0.062^{* * *}(0.011)$ & $49 \%$ & $-0.032^{* * *}(0.010)$ \\
\hline Edad & 36 & $6.581^{* * *}(0.294)$ & 36 & $5.101^{* * *}(0.306)$ & 36 & $4.956^{* * *}(0.278)$ \\
\hline GBA & $53 \%$ & $0.024^{* * *}(0.006)$ & $51 \%$ & $0.274^{* * *}(0.006)$ & $50 \%$ & $-0.276^{* * *}(0.006)$ \\
\hline $\mathrm{NOA}$ & $10 \%$ & $-0.070 * * *(0.002)$ & $10 \%$ & $-0.074^{* * *}(0.002)$ & $10 \%$ & $-0.078^{* * *}(0.002)$ \\
\hline NEA & $5 \%$ & $-0.030 * * *(0.001)$ & $5 \%$ & $-0.036^{* * *}(0.001)$ & $6 \%$ & $-0.039^{* * * *}(0.001)$ \\
\hline CUYO & $6 \%$ & $-0.031^{* * *}(0.002)$ & $6 \%$ & $-0.033^{* * *}(0.002)$ & $7 \%$ & $-0.042^{* * *}(0.002)$ \\
\hline Pampeana & $24 \%$ & $-0.134^{* * *}(0.004)$ & $24 \%$ & $-0.149^{* * *}(0.004)$ & $24 \%$ & $-0.133^{* * *}(0.003)$ \\
\hline Patagonica & $3 \%$ & $0.029^{* * *}(0.002)$ & $3 \%$ & $0.018^{* * *}(0.002)$ & $4 \%$ & $0.015^{* * *}(0.002)$ \\
\hline Primaria Completa & $44 \%$ & $0.057^{* * *}(0.010)$ & $42 \%$ & $0.031^{* * *}(0.011)$ & $41 \%$ & $-0.001(0.010)$ \\
\hline Secundaria Completa & $36 \%$ & $-0.060 * * *(0.009)$ & $37 \%$ & $-0.028^{* * *}(0.010)$ & $39 \%$ & $0.004(0.010)$ \\
\hline Universitaria Completa & $13 \%$ & $-0.054^{* * *}(0.005)$ & $15 \%$ & $-0.048^{* * *}(0.006)$ & $16 \%$ & $-0.048^{* * *}(0.006)$ \\
\hline Ocupado & $60 \%$ & $0.024 * *(0.010)$ & $62 \%$ & $0.031 * * *(0.010)$ & $61 \%$ & $0.051^{* * *}(0.010)$ \\
\hline Desocupado & $8 \%$ & $0.006(0.006)$ & $6 \%$ & $-0.010 * *(0.004)$ & $5 \%$ & $-0.008^{*}(0.004)$ \\
\hline Inactivo & $32 \%$ & $-0.030 * * *(0.009)$ & $33 \%$ & $-0.021 * *(0.010)$ & $34 \%$ & $-0.043^{* * *}(0.009)$ \\
\hline
\end{tabular}

Notas: errores estándar robustos entre paréntesis, *** significativo al $1 \%$, ** significativo al $5 \%$, * significativo al $10 \%$. La columna"nativos" presenta el valor medio de cada variable para el grupo poblacional nativos mientras que la columna "inmigrante" muestra a diferencia del grupo poblacional inmigrante con respecto a la media de los nativos. 
Cuadro C-Regresión para el logaritmo del salario horario de la ocupación principal.

\section{Regresión para el logaritmo del salario horario}

\begin{tabular}{lcll}
\hline Inmigrante & $-0.104^{* * *}(0.010)$ & Operativos & $0.144^{* * *}(0.006)$ \\
Sexo & $0.110^{* * *}(0.005)$ & NOA & $-0.367^{* * *}(0.005)$ \\
Edad & $0.030^{* * *}(0.001)$ & NEA & $-0.411^{* * *}(0.005)$ \\
Edad ${ }^{2}$ & $-0.0003^{* * *}(0.000)$ & Cuyo & $-0.237^{* * *}(0.005)$ \\
Primaria completa & $0.131^{* * *}(0.010)$ & Pampeana & $-0.0771^{* * *}(0.004)$ \\
Secundaria completa & $0.373^{* * *}(0.011)$ & Patagónica & $0.235^{* * *}(0.005)$ \\
Universitario completo & $0.598^{* * *}(0.012)$ & Año 2015 & $0.604^{* * *}(0.009)$ \\
Unido & $0.034^{* * *}(0.006)$ & Año 2014 & $0.657^{* * *}(0.009)$ \\
Casado & $0.099^{* * *}(0.005)$ & Año 2013 & $0.616^{* * *}(0.010)$ \\
Separado & $0.034^{* * *}(0.006)$ & Año 2012 & $0.657^{* * *}(0.009)$ \\
Viudo & $0.019^{* * *}(0.016)$ & Año 2011 & $0.546^{* * *}(0.010)$ \\
Patrón & $0.114^{* * *}(0.014)$ & Año 2010 & $0.507^{* * *}(0.010)$ \\
Empleado & $0.311^{* * *}(0.006)$ & Año 2009 & $0.462^{* * *}(0.009)$ \\
Agro y minas & $-0.082^{* * *}(0.019)$ & Año 2008 & $0.486^{* * *}(0.009)$ \\
Industria & $-0.096^{* * *}(0.006)$ & Año 2007 & $0.316^{* * *}(0.009)$ \\
Construcción & $-0.087^{* * *}(0.007)$ & Año 2006 & $0.209^{* * *}(0.009)$ \\
Comercio & $-0.181^{* * *(0.006)}$ & Año 2005 & $0.078^{* * *}(0.010)$ \\
Doméstico & $-0.119^{* * *}(0.008)$ & Constante & $-0.209^{* * *}(0.026)$ \\
Profesional & $0.595^{* * *}(0.009)$ & & \\
Técnicos & $-0.398^{* * *}(0.007)$ & & \\
Observaciones & & 248,933 & \\
$R^{2}-$ ajustado & 0.377 & \\
\hline & & & \\
\hline
\end{tabular}

Notas: errores estándar robustos entre paréntesis, ${ }^{* * *}$ significativo al $1 \%,{ }^{* *}$ significativo al $5 \%,{ }^{*}$ significativo al $10 \%$. La variable sexo es $=1$ si el individuo es hombre. Para las variables de educación la variable omitida es "Sin educación", para las de estado civil la variable omitida es "soltero", para las de categoría ocupacional la variable omitida es "cuenta propia", para de sector de actividad la variable omitida es "servicios", para las de categoría ocupacional la variable omitida es "no calificado" y para las regiones la región omitida es "GBA". 
Figura B -Efecto características en distintos cuantiles del ingreso.
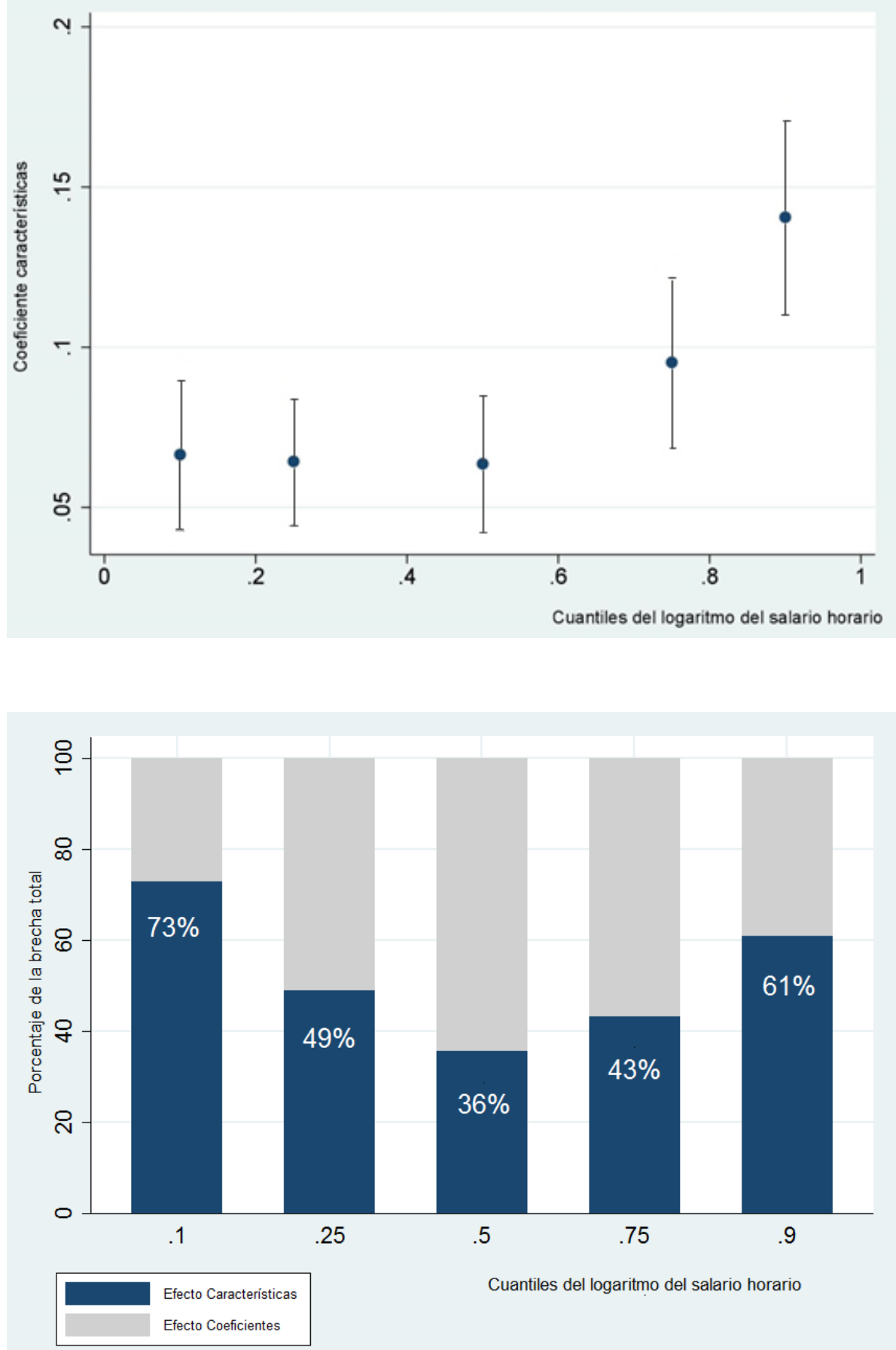

Nota: las barras de la primera figura representan intervalos de confianza al $95 \%$. La Segunda figura muestra qué proporción representa el coeficiente de la primera figura en la brecha total ("forma de U"). 
Figura C - Evolución del coeficiente de residencia.
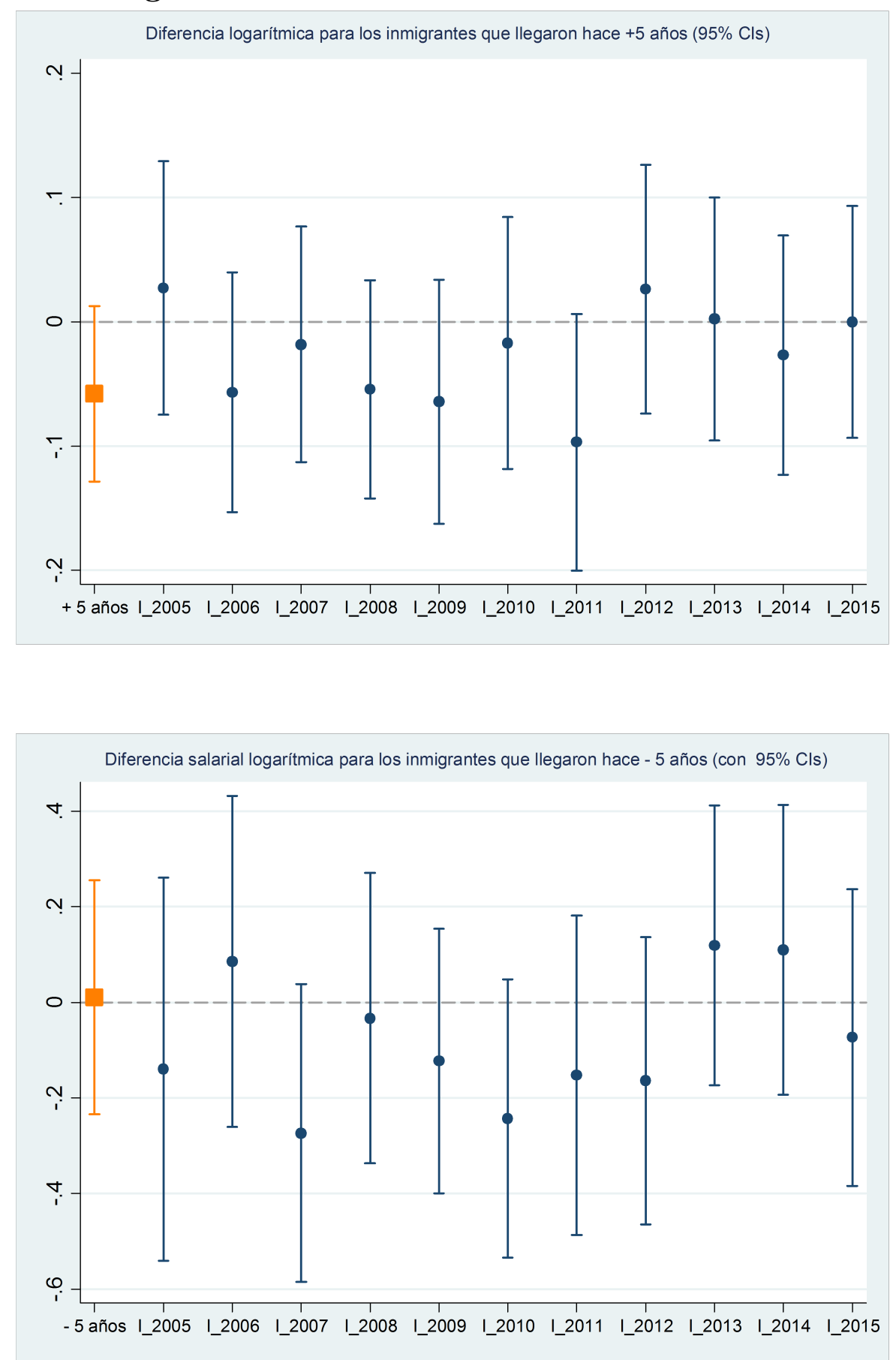

Nota: se presenta de color naranja el coeficiente para cohorte de residencia en el año base (2004) y luego se muestra la evolución de dicho coeficiente para cada uno de los años siguientes. Las barras de la figura representan intervalos de confianza al $95 \%$. 
Figura D - Diferencia salarial de los inmigrantes respecto de los nativos según cohortes de llegada por años.

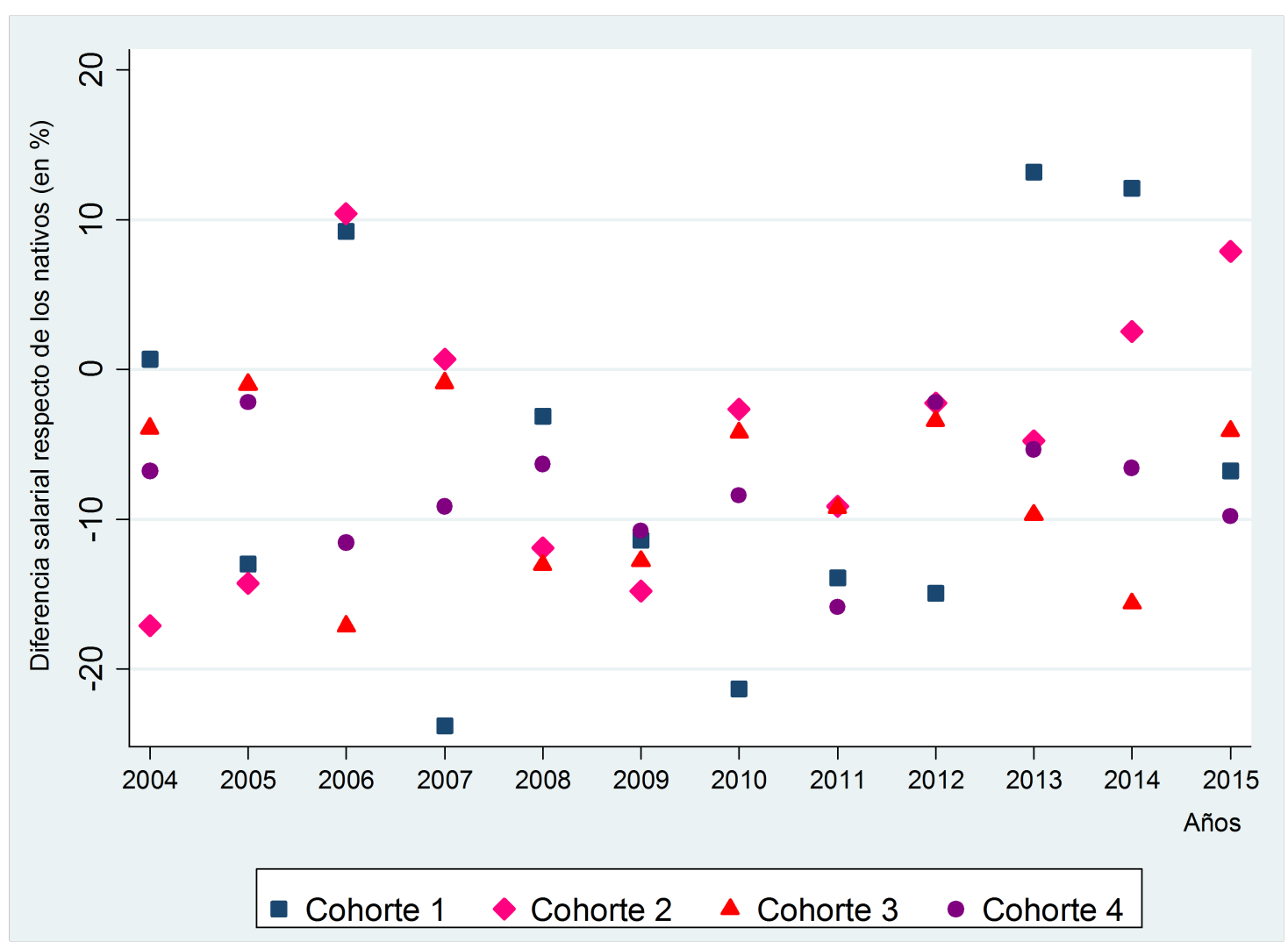

Nota: la diferencia salarial en cada año y cada cohorte se calcula como la suma del coeficiente de cohorte más el coeficiente de la interacción de la cohorte con el año. De este proceso se obtiene $\gamma$, es decir la diferencia salarial de cada cohorte en puntos logarítmicos en relación a los nativos. Luego, para obtener el porcentaje presentado en la figura, se calcula $e^{\gamma}-1$. 